Revue des patrimoines

\title{
Un modèle de piété et de charité : le décor de la chapelle seigneuriale de Lachapelle-sous-Gerberoy (Oise) et son cycle de la vie de saint Eustache
}

\section{Géraldine Victoir}

\section{OpenEdition}

\section{Journals}

Édition électronique

URL : http://journals.openedition.org/insitu/10662

DOI : 10.4000/insitu.10662

ISSN : 1630-7305

Éditeur

Ministère de la culture

Référence électronique

Géraldine Victoir, «Un modèle de piété et de charité : le décor de la chapelle seigneuriale de Lachapelle-sous-Gerberoy (Oise) et son cycle de la vie de saint Eustache », In Situ [En ligne], 22 | 2013, mis en ligne le 22 novembre 2013, consulté le 01 mai 2019. URL : http://journals.openedition.org/ insitu/10662 ; DOI : 10.4000/insitu.10662

Ce document a été généré automatiquement le 1 mai 2019.

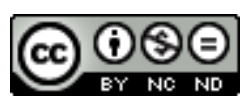

In Situ Revues des patrimoines est mis à disposition selon les termes de la licence Creative Commons Attribution - Pas d'Utilisation Commerciale - Pas de Modification 4.0 International. 


\title{
Un modèle de piété et de charité : le décor de la chapelle seigneuriale de Lachapelle-sous-Gerberoy (Oise) et son cycle de la vie de saint Eustache
}

\author{
Géraldine Victoir
}

Communication présentée lors des journées d'études consacrées à l'Actualité de la recherche en

peinture murale, organisées par le musée des Monuments français les 25 et 26 octobre 2011, à la Cité de l'architecture et du patrimoine.

La petite église paroissiale de Lachapelle-sous-Gerberoy, aux confins de l'Oise, recèle d'importants vestiges de décors peints (fig. $\mathbf{n}^{\circ} \mathbf{1}$ ). La minuscule chapelle (environ $3 \times 3 \mathrm{~m}$ ) au nord du chœur, en particulier, conserve un exceptionnel ensemble figuré dont le sujet principal est un rare cycle de la vie de saint Eustache (fig. $\left.\mathbf{n}^{\circ} \mathbf{2}\right)$ (fig. $\mathbf{n}^{\circ} \mathbf{3}$ ). Bâtie en moellon de silex, avec chaînages d'angle en pierre de taille, elle a été accolée à un clocher plus ancien, comme l'indique la jonction de son mur oriental avec l'ancien contrefort de la tour (fig. $\left.\mathbf{n}^{\circ} \mathbf{4}\right)$. Éclairée de deux baies, au nord et à l'est, elle est couverte d'une voûte en berceau brisé en pierre datant vraisemblablement de la fin du XIII ${ }^{\mathrm{e}}$ siècle ou du XIV siècle. Le décor, découvert en 1990 et dégagé en 1992, est fragmentaire mais suffisant pour en restituer le programme ${ }^{1}$. 
Figure 1
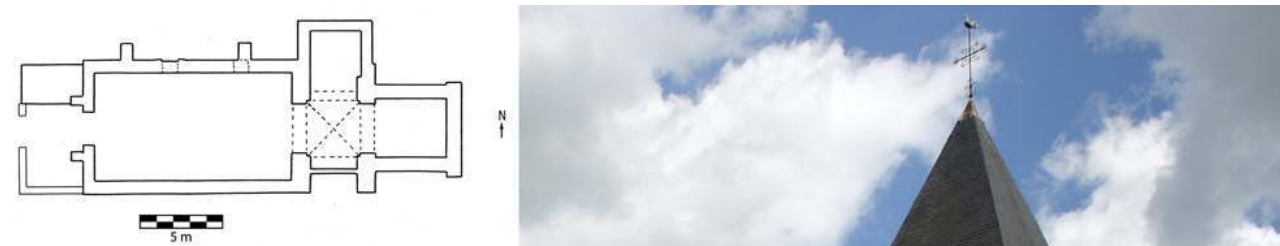

$=-5 \mathrm{~m}=$

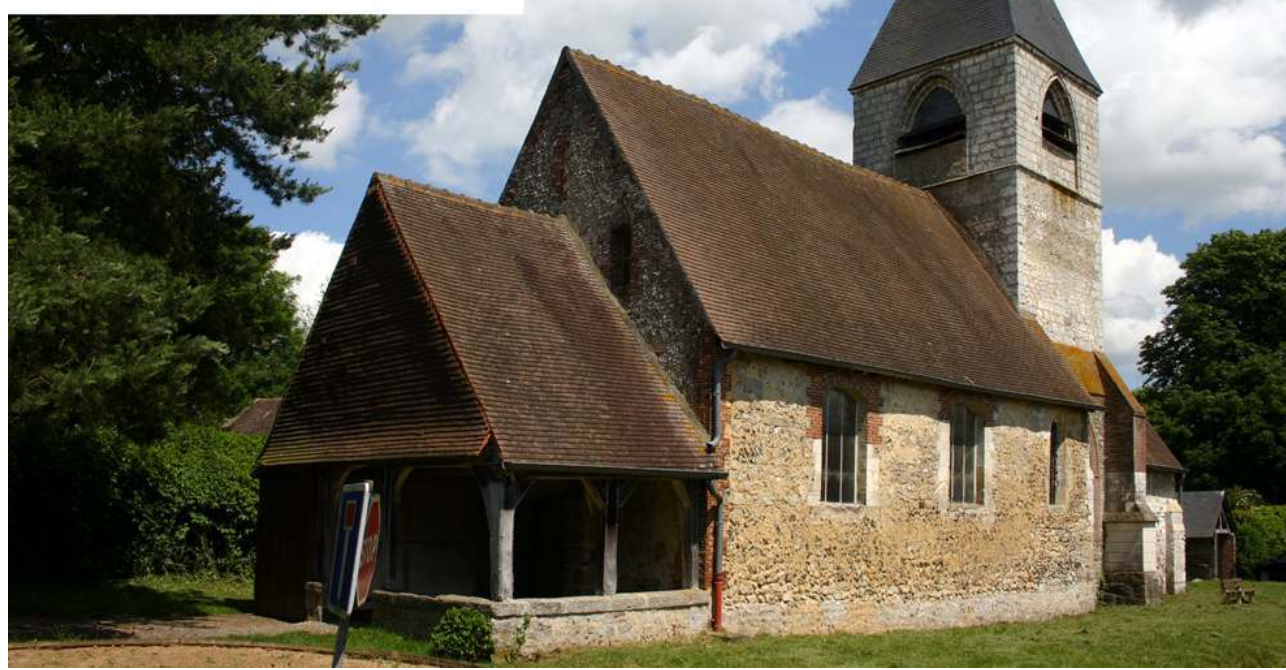

Église de Lachapelle-sous-Gerberoy, mai 2007, et plan (d'après Gaultier).

Phot. Victoir, G. (c) G. Victoir.

Figure 2

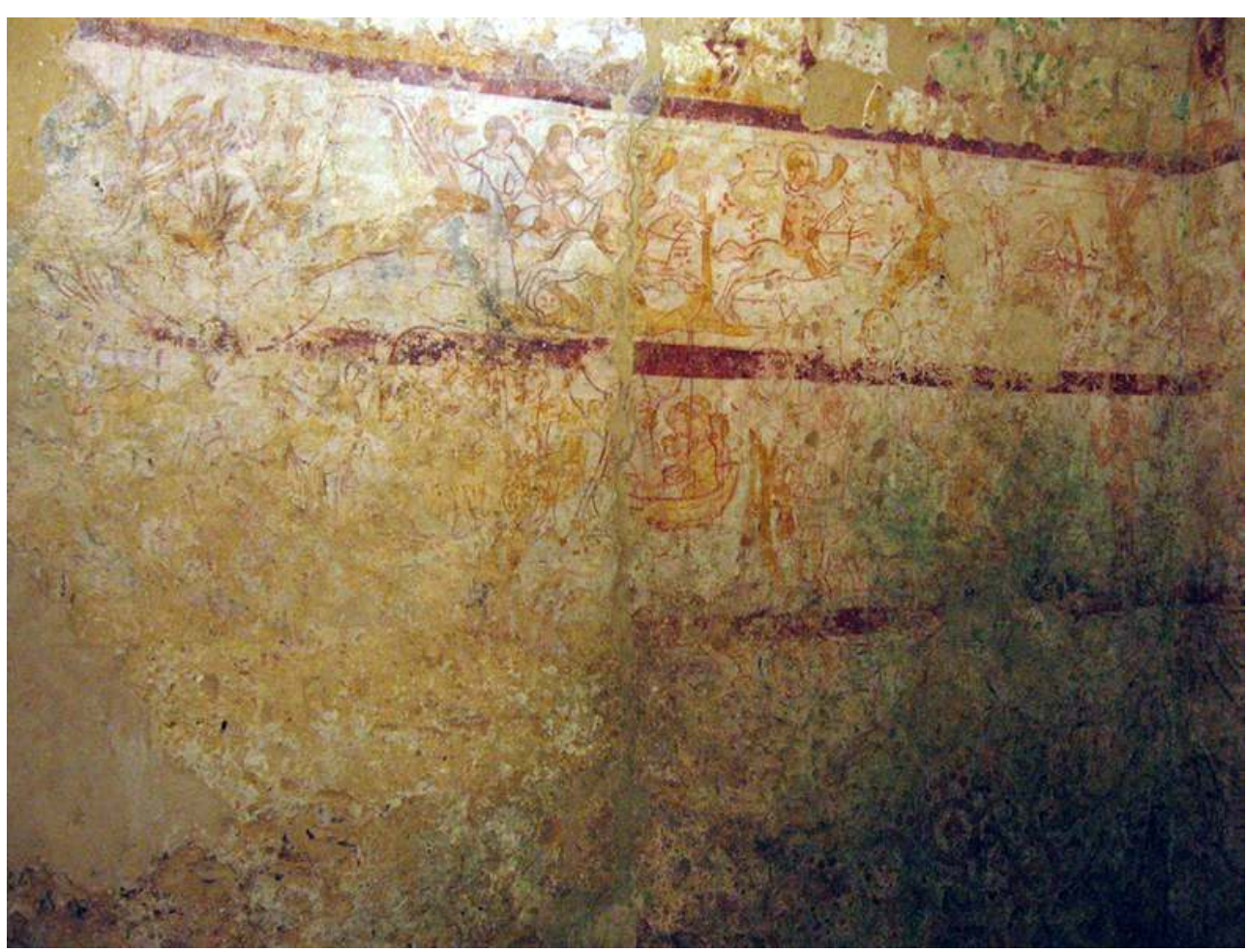

Chapelle nord de l'église : mur occidental, septembre 2005.

Phot. Victoir, G. (c) G. Victoir. 
Figure 3

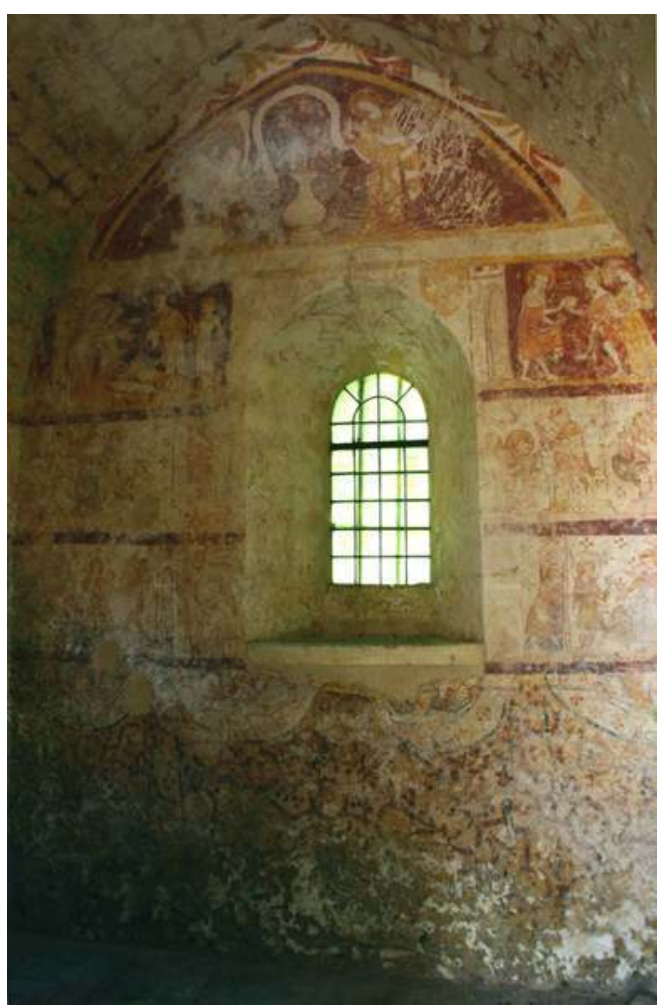

Chapelle nord de l'église : mur nord, mai 2007.

Phot. Victoir, G. (c) G. Victoir. 
Figure 4

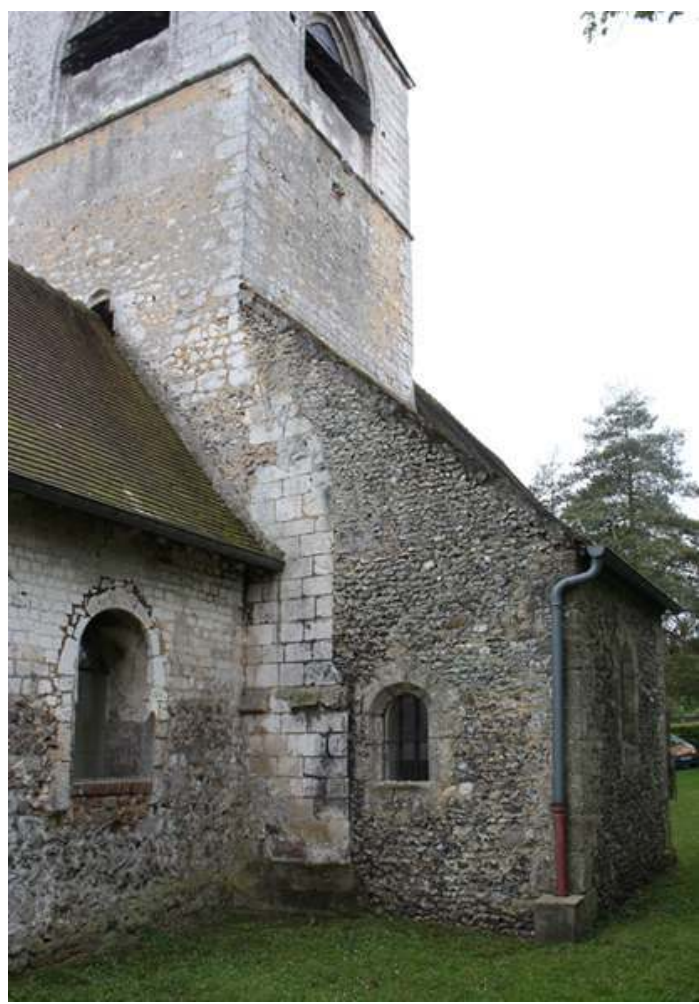

Chapelle en silex, accolée au nord du clocher de l'église, entre les anciens contreforts, mai 2012.

Phot. Victoir, G. (c) G. Victoir.

La voûte était couverte de vingt-cinq quadrilobes étoilés contenant des saints sur un fond ocre rouge alternativement clair et foncé mais les infiltrations d'eau n'en ont laissé que des vestiges (fig. $\mathbf{n}^{\circ} 5$ ). Excepté du côté sud, percé d'un arc menant vers le chœur, les murs étaient divisés en quatre registres figurés. Presque rien ne subsiste du côté oriental. Sur les murs ouest et nord, le registre inférieur est orné d'une imitation de draperies accrochées à des tringles tenues par des anges. Les deuxième et troisième registres, sur fond blanc, sont occupés par un cycle de la vie de saint Eustache. Le registre supérieur s'étendait au pied de la voûte, mais a subi le même sort que les quadrilobes étoilés. Seules deux scènes subsistent sur le mur nord, présentées sur un fond rouge : on y reconnaît un enterrement et une distribution d'aumônes. La partie haute en arc brisé de ce même mur est entièrement occupée par une Annonciation bordée d'une frise végétale stylisée. Deux blasons peints sur les écoinçons de la baie nord identifiaient les commanditaires. Enfin, sur les ébrasements de cette fenêtre, deux saintes sont entourées de rinceaux et de fleurettes, dont on retrouve quelques vestiges sur les ébrasements de la baie orientale. 


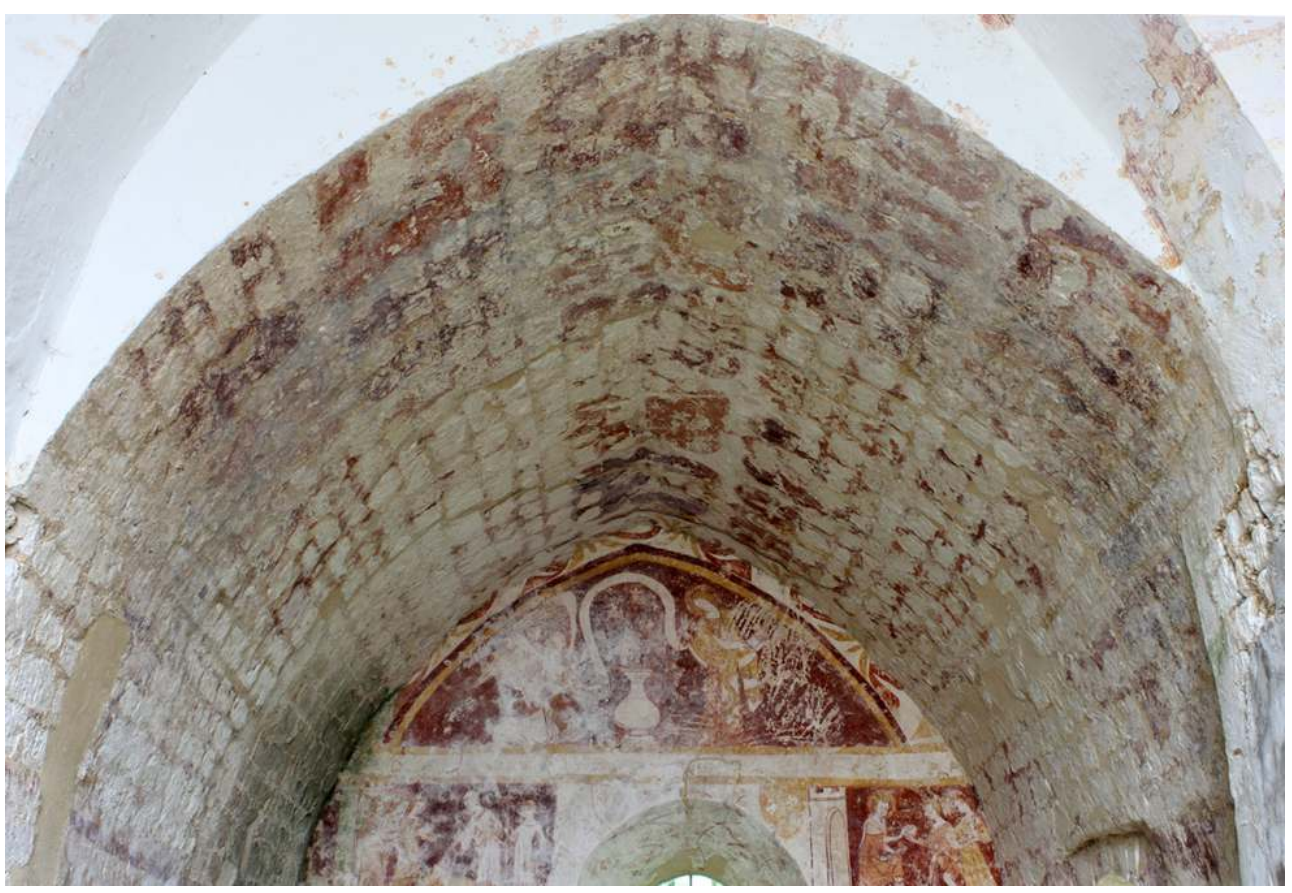

Chapelle nord, voûte, mai 2012.

Phot. Victoir, G. () G. Victoir.

3 Cet exceptionnel décor a été brièvement publié par P. Bonnet-Laborderie, qui l'a daté de la fin du XIII ${ }^{\mathrm{e}}$ siècle ou du début du XIV ${ }^{\mathrm{e}}$ siècle ${ }^{2}$. L'examen des costumes incite à réévaluer cette date : la femme d'Eustache porte une robe ajustée avec des coudières, élongations extravagantes des manches apparues dans les années $1340^{3}$ (voir fig. n²0). De même, le capuchon d'Eustache descendant sur les épaules est comparable à ceux portés dans le Roman d'Alexandre daté des mêmes années (par exemple fol. 57r) http://image.ox.ac.uk/ show?collection=bodleian\&manuscript=msbodl $264^{4}$. Les similitudes du style avec celui qui avait déjà cours un demi-siècle plus tôt font par ailleurs de cet ensemble un exemple de la persistance des conventions graphiques en vigueur depuis le règne de saint Louis ${ }^{5}$.

4 Le peintre a travaillé sur un enduit probablement appliqué à la main ${ }^{6}$. Un premier cycle de la vie de saint Eustache en un seul grand registre a été dessiné sur le mur. Ce premier projet a été abandonné pour celui qui nous est parvenu, en deux registres, mais la perte partielle des couches picturales définitives a eu pour conséquence de le rendre par endroit visible (voir fig. $\mathrm{n}^{\circ} 22$ ). Une correction similaire du dessin préparatoire nous est parvenue à Landes (Charente-Maritime), où un chasseur a changé de position ${ }^{7}$, et dans la chapelle du tombeau des enfants de Charles VII à la cathédrale de Tours (1323), où les dimensions de la scène de la décollation, sur le mur oriental, ont été réduites ${ }^{8}$.

\section{Les saints}


Figure 6

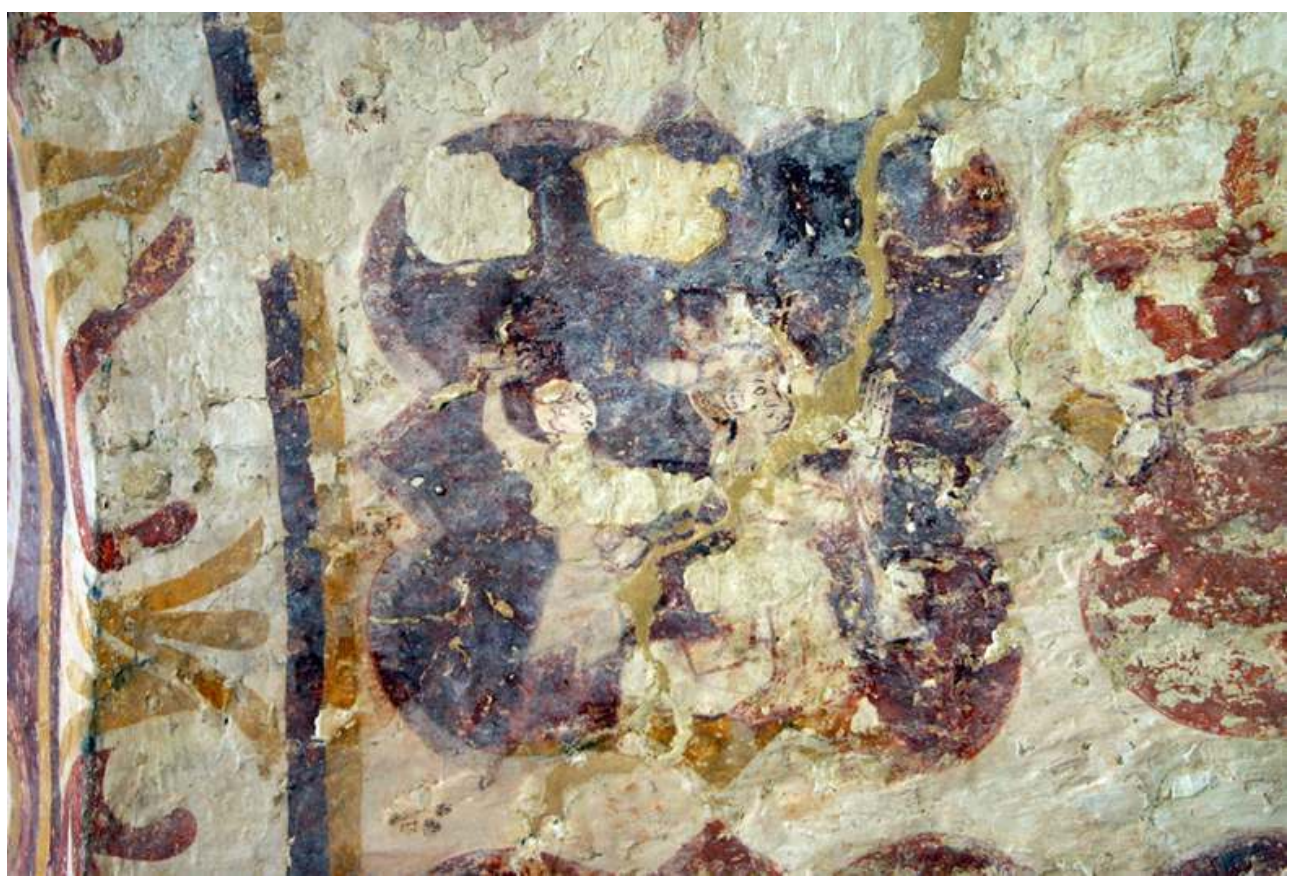

Détail de la voûte : le martyre de saint Étienne, mai 2007.

Phot. Victoir, G. (c) G. Victoir.

Figure 7

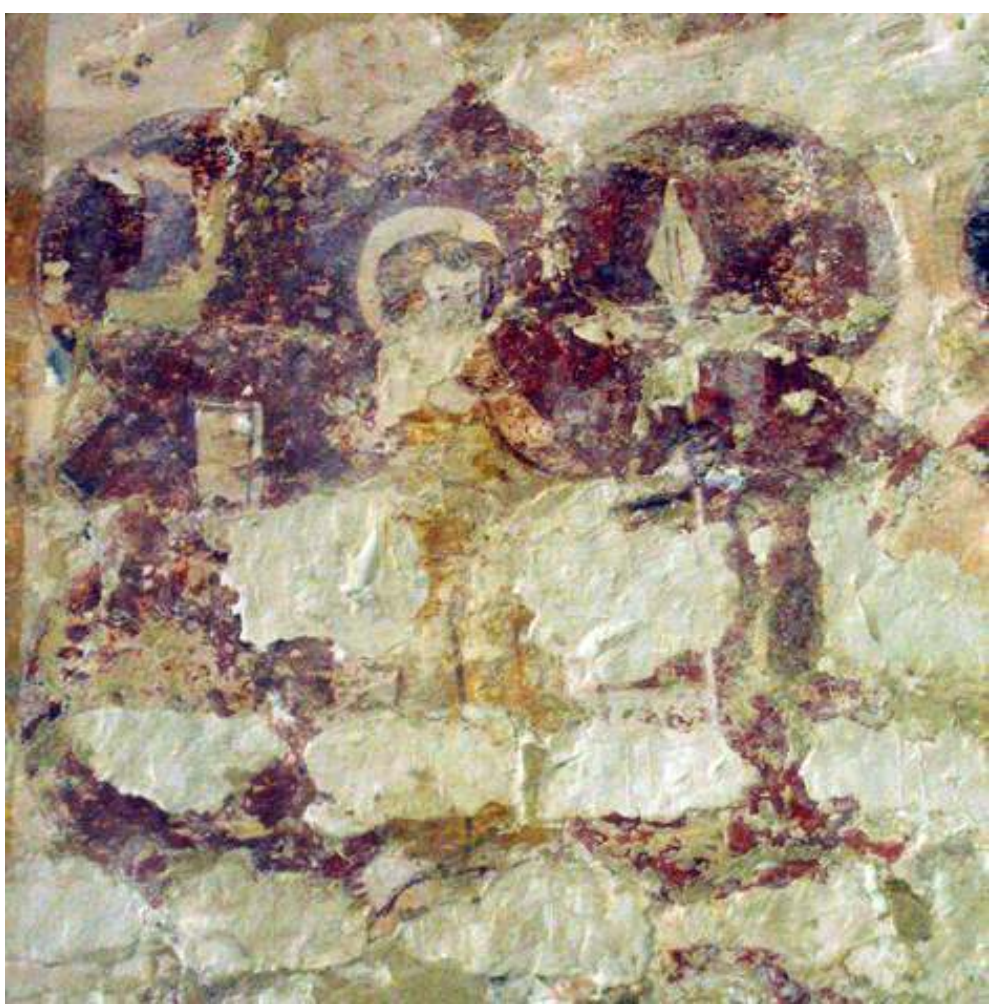

Détail de la voûte : saint Thomas, septembre 2005.

Phot. Victoir, G. @ G. Victoir. 
Seuls cinq des quadrilobes de la voûte (voir fig. $n^{\circ} 5$ ) sont assez bien conservés pour en identifier les personnages. Saint Étienne y est représenté agenouillé, les mains jointes, pendant sa lapidation (fig. $\mathbf{n}^{\circ} \mathbf{6}$ ), selon l'iconographie traditionnelle rencontrée par exemple au portail occidental de la cathédrale de Bourges, vers $1240^{\circ}$. Saint Thomas tient un livre et une lance, instrument de son martyre (fig. $\mathbf{n}^{\circ} \mathbf{7}$ ), comme sur la chape anglaise de Syon vers 1300 http://collections.vam.ac.uk/item/093171/syon-cope-the-syon-cope/10 . André est représenté crucifié, la croix tournée à l'horizontale (fig. $\left.\mathbf{n}^{\circ} \mathbf{8}\right)$, comme sur une peinture murale de l'église de Lavaudieu ${ }^{11}$. L'ecclésiastique décapité (fig. $\mathbf{n}^{\circ} \mathbf{9}$ ) pourrait être saint Denis, saint Nicaise ou saint Piat, respectivement évêques de Paris, Reims et Tournai, tous trois céphalophores apparaissant, par exemple, dans le Livre d'images de Madame Marie. Enfin, le martyre d'un saint à moitié dénudé, écartant les bras et encadré de deux personnages plus petits (fig. $\mathbf{n}^{\circ} \mathbf{1 0}$ ) peut être identifié comme celui de saint Blaise écorché par des peignes à carder, comme dans un vitrail de la cathédrale de Poitiers http://www.medievalart.org.uk/PoitiersWindows/113b_Pages/

Poitiers_Bay113b_Panel21.htm ${ }^{12}$. La présence de nombreux saints dans des quadrilobes semble peu usuelle sur la voûte d'une chapelle.

Figure 8

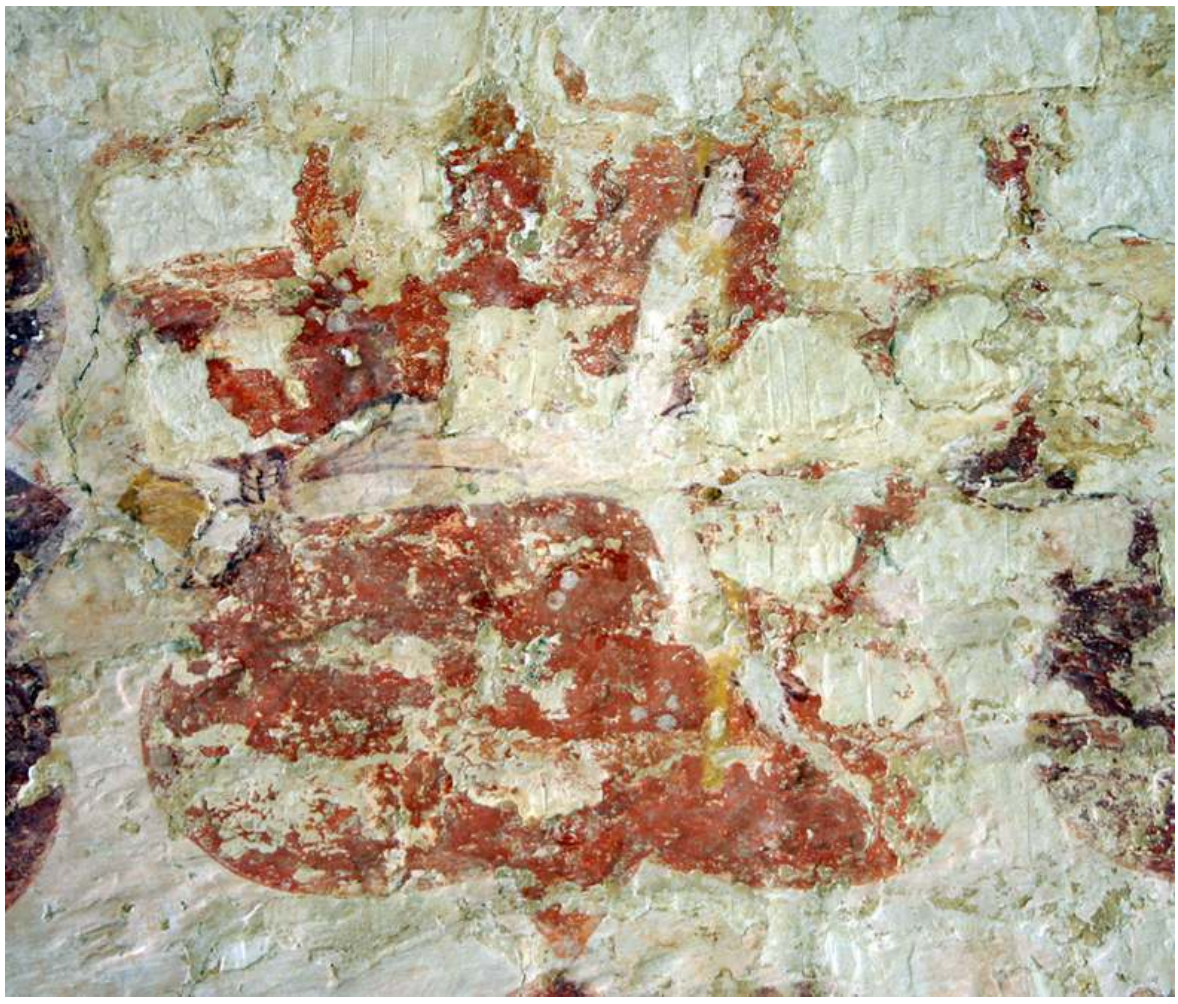

Détail de la voûte : saint André, mai 2007.

Phot. Victoir, G. @ G. Victoir. 
Figure 9

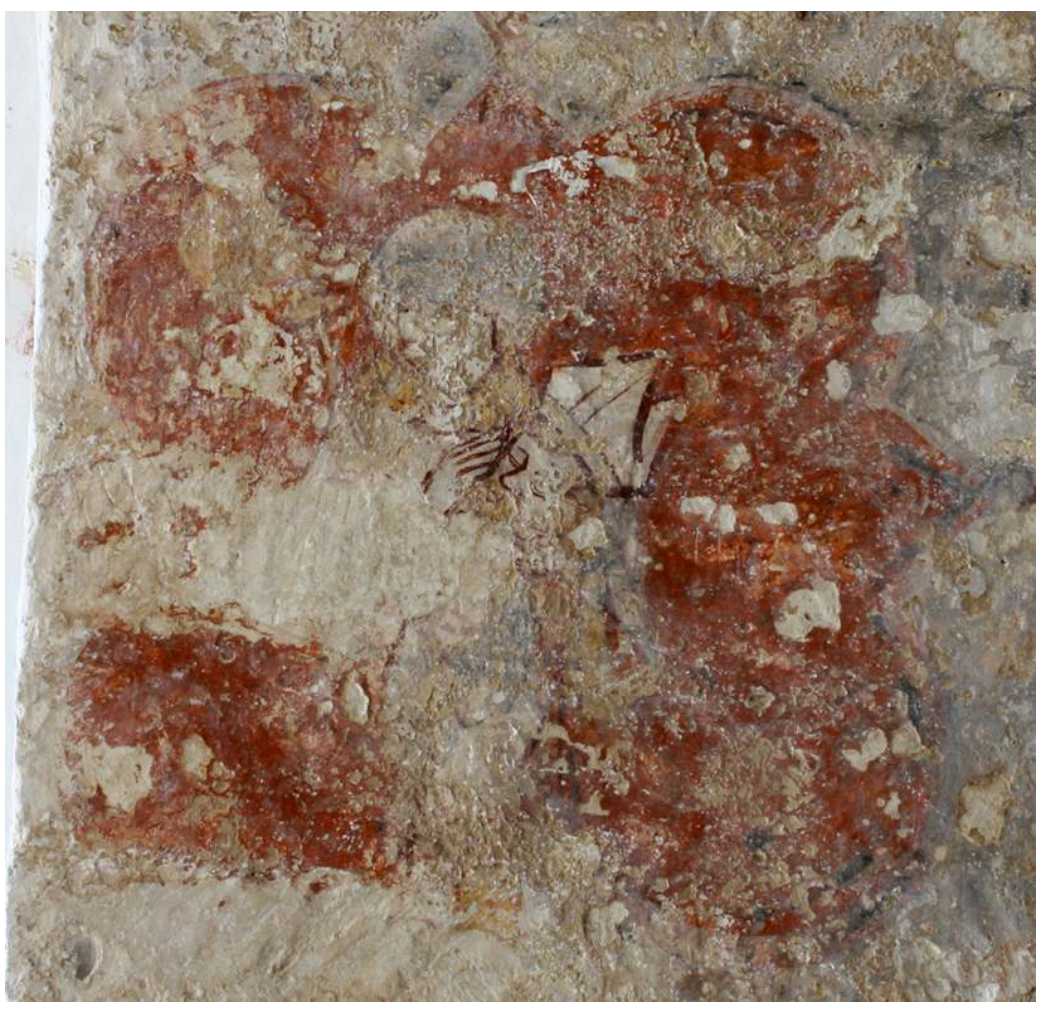

Détail de la voûte : saint céphalophore, mai 2012.

Phot. Victoir, G. (c) G. Victoir. 
Figure 10

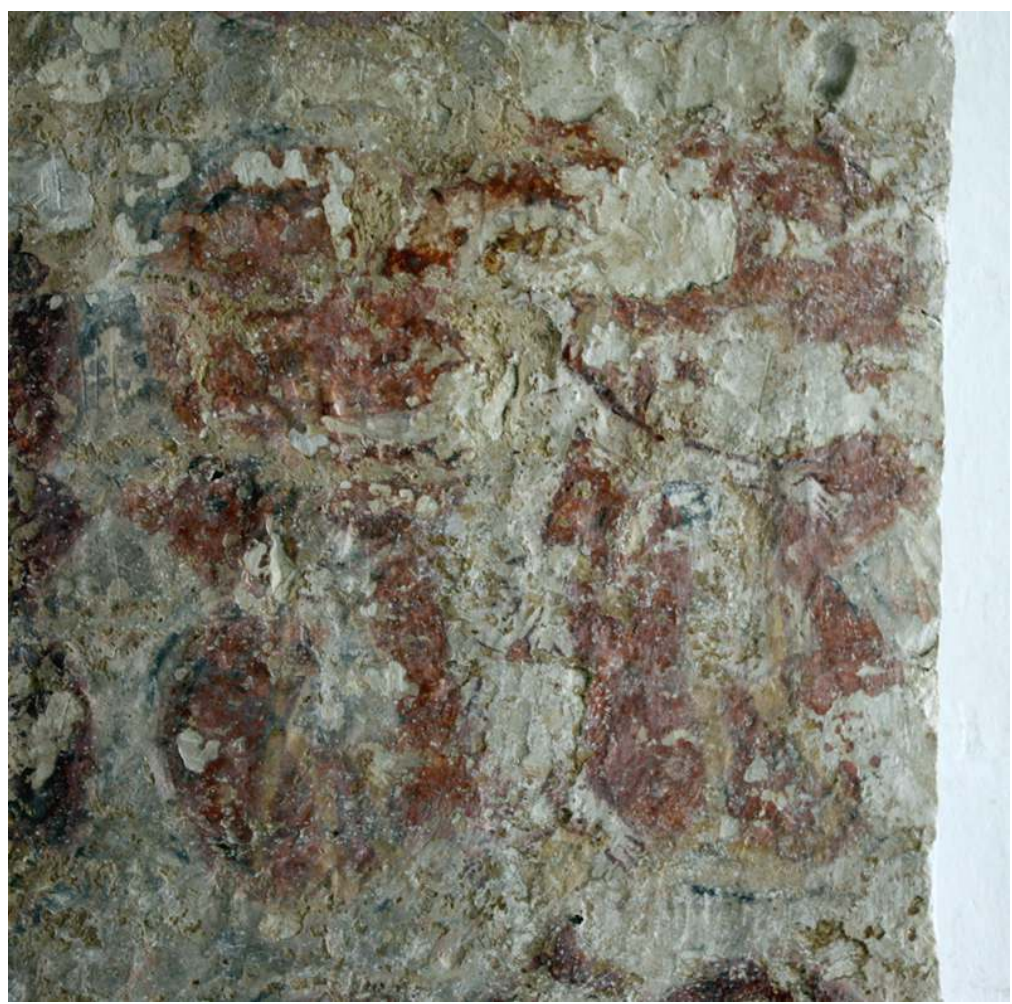

Détail de la voûte : saint Blaise, mai 2012.

Phot. Victoir, G. ( ) G. Victoir.

Les quadrilobes étoilés ont été utilisés dans différents media depuis le milieu du XIII siècle environ ${ }^{13}$, dans les vitraux (par exemple à Fécamp, vers 1275$)^{14}$, les façades d'églises (cathédrales d'Auxerre et de Rouen) ${ }^{15}$ et la peinture murale (Le Mesnil-Aubert, Manche, $\mathrm{XIV}^{\mathrm{e}}$ siècle $)^{16}$, mais l'iconographie de ces sites n'inclut pas de série de saints. Cette disposition rappelle la chape brodée de Syon, déjà mentionnée, dont la surface est occupée par des quadrilobes contenant la Crucifixion, le Couronnement de la Vierge et de nombreux saints http://collections.vam.ac.uk/item/093171/syon-cope-the-syon-cope/, protecteurs réunis sur le vêtement de l'évêque. Bien que le contexte soit différent, il semble que ce soit cette même volonté d'obtenir une image de l'assemblée céleste susceptible de protéger le commanditaire qui ait présidé à Lachapelle-sous-Gerberoy. 
Figure 11

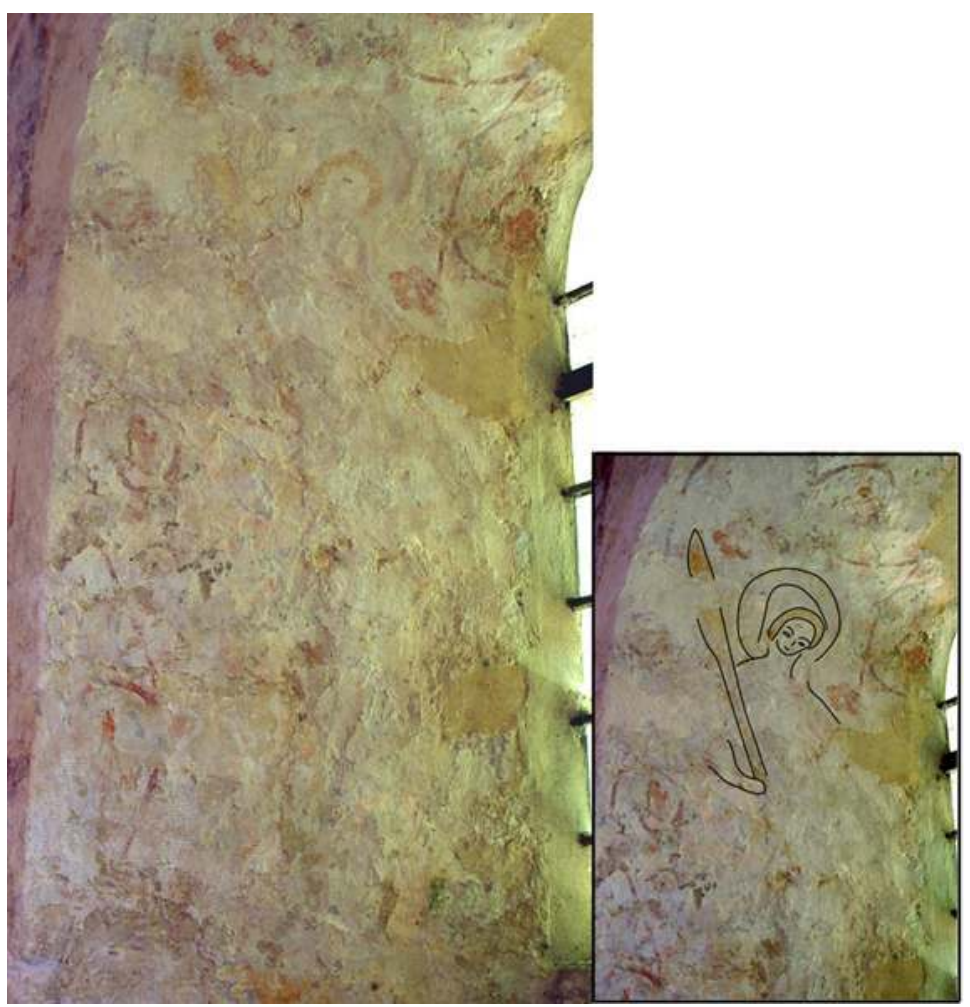

Baie nord, ébrasement ouest : sainte tenant une palme, mai 2007.

Phot. Victoir, G. ( ) G. Victoir.

7 Deux saintes martyres tenant une palme occupent les ébrasements de la baie nord (fig. $\mathbf{n}^{\circ}$ 11) (fig. $\mathbf{n}^{\circ}{ }^{12}$ ). La première, à l'est, doit être sainte Barbe en raison de la tour qu'elle tient dans la main gauche. La seconde a perdu son attribut mais c'est peut-être sainte Catherine, souvent associée à sainte Barbe. Ces saintes, isolées de leurs équivalents masculins conservés sur la voûte, étaient peut-être destinées à protéger la femme du commanditaire. Nous verrons en effet que le décor de la chapelle reflète les intérêts d'un couple. 
Figure 12

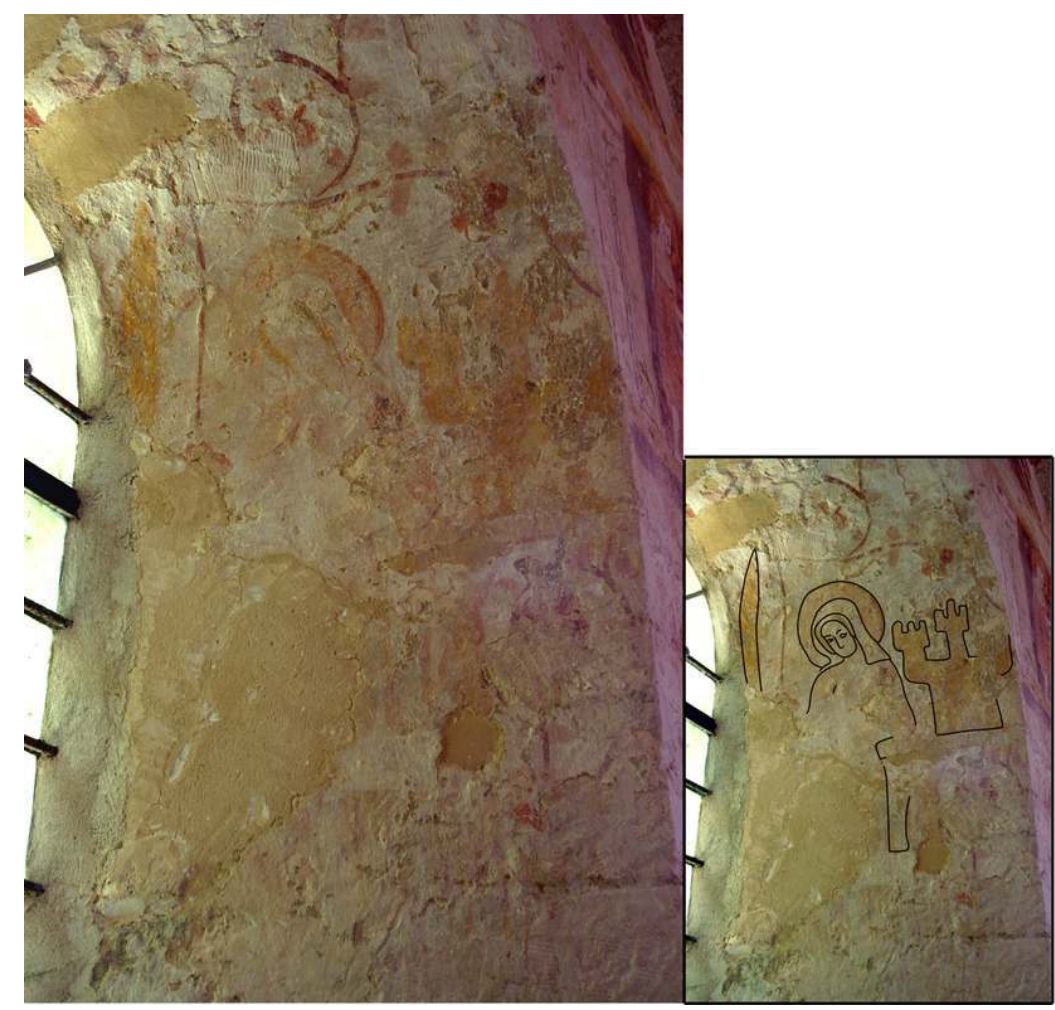

Baie nord, ébrasement est : sainte Barbe, mai 2007.

Phot. Victoir, G. ( ) G. Victoir.

\section{Les anges du registre inférieur}

8 Le registre inférieur des murs ouest et nord est occupé par des tentures fictives décorées de médaillons, dont les tringles sont tenues par des anges (fig. $\left.\mathbf{n}^{\circ}{ }^{13}\right)$ (fig. $\mathbf{n}^{\circ}{ }^{14}$ ). Des tissus étaient fréquemment peints en soubassement, en imitation des véritables tentures que l'on avait coutume d'accrocher contre les murs. Les anges, en revanche, occupent plus rarement cette fonction. Peut-être sont-ils apparentés à ceux tenant un drap d'honneur derrière la Vierge, courants dans la peinture italienne de la fin du XIII et du XIVe siècle, par exemple dans une œuvre conservée à Columbia http:// www.columbiamuseum.org/art/artwork.php?coliD $=46^{17}$. Dans des régions plus septentrionales, des anges tenant des livres fermés étaient peints derrière les tentures de soubassement dans la salle capitulaire de la cathédrale de Worcester au XIII ${ }^{\mathrm{e}}$ siècle $^{18}$. Contemporain ou légèrement postérieur, le décor de la chapelle Saint-Étienne de l'abbaye de Westminster, connu par des dessins et daté entre 1350 et 1363, comprenait des anges saisissant les tentures plutôt que des tringles, comme sur les peintures italiennes ${ }^{19}$. Un peu plus tard, la galerie de la Reine à l'hôtel Saint-Pol à Paris, probablement décorée dans les années 1360, est ainsi décrite pas Sauval: «là, de côté et d'autre, quantité d'anges tendoient une courtine des livrées du roi $»^{20}$. Le peintre de Lachapelle-sous-Gerberoy connaissait probablement une œuvre récente du nord de la France présentant ce motif, œuvre qui témoignait de l'intérêt renouvelé pour l'art transalpin chez les peintres français dans le deuxième quart du XIV ${ }^{\mathrm{e}}$ siècle ${ }^{21}$. 


\section{Figure 13}

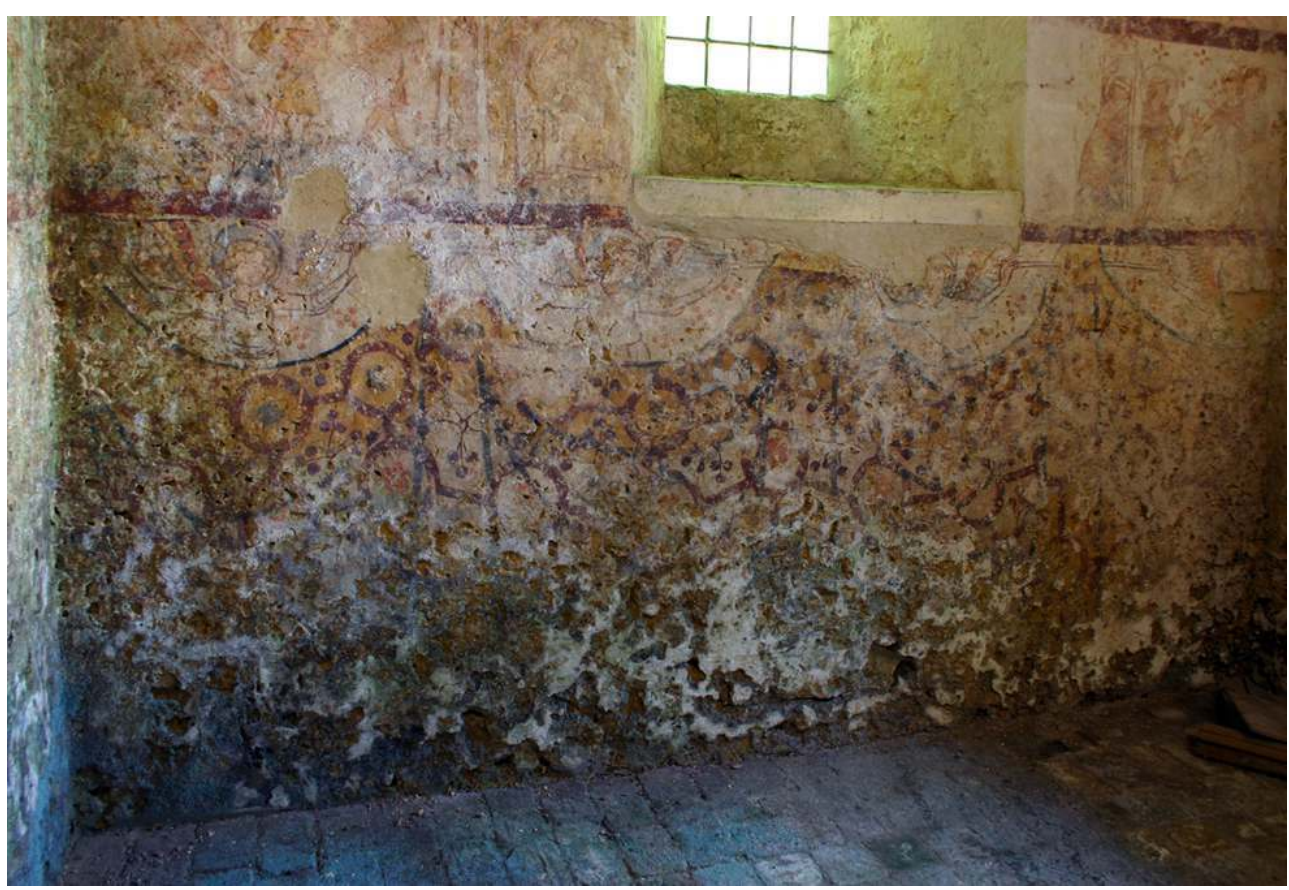

Mur nord, registre inférieur : anges tenant les tringles d'une tenture, mai 2007.

Phot. Victoir, G. (c) G. Victoir.

\section{Figure 14}

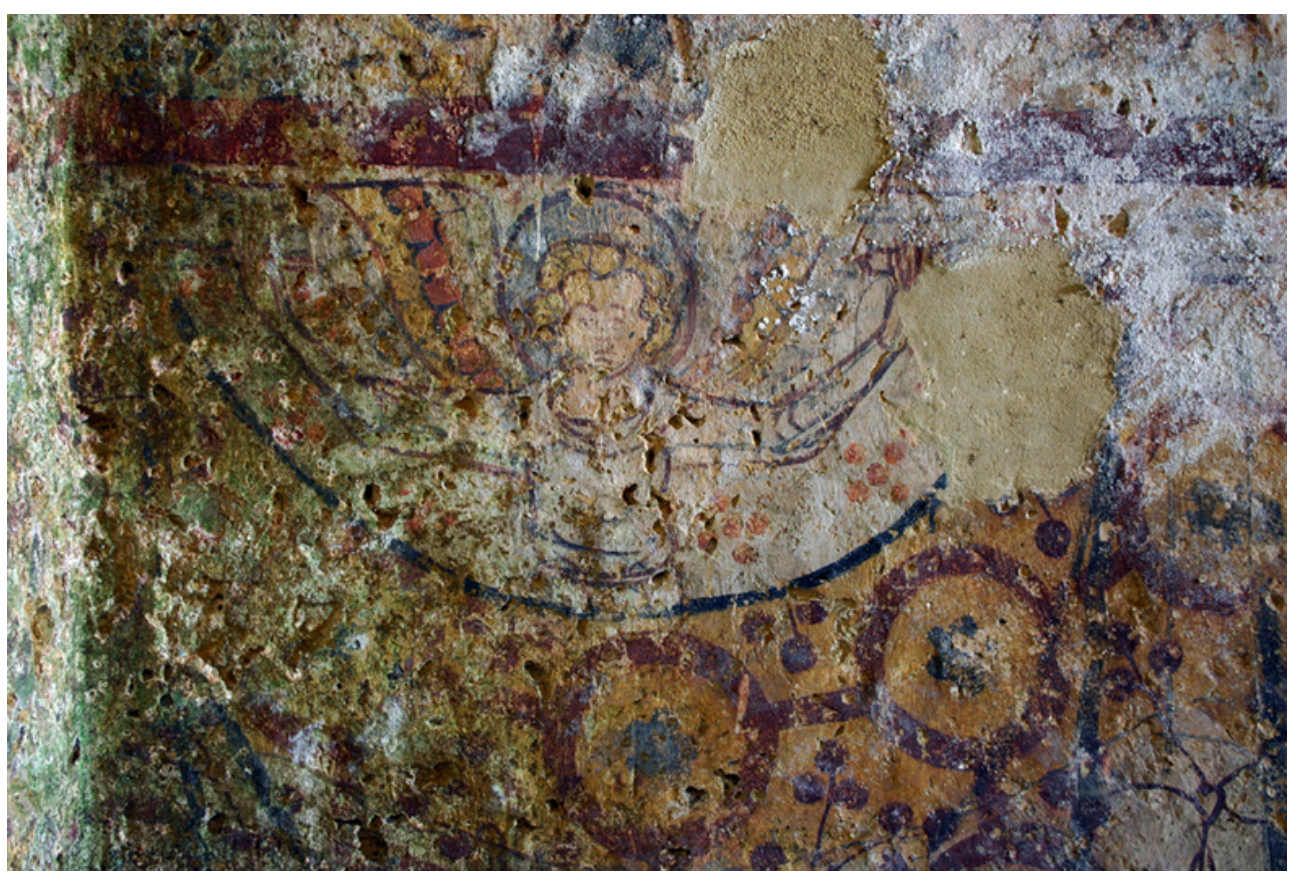

Détail de la Figure 12 : un ange, mai 2007.

Phot. Victoir, G. (c) G. Victoir. 


\section{Le cycle de la vie d'Eustache}

9 La vie de saint Eustache se déployait sur les deux registres centraux. Cette légende était populaire en Orient depuis le VIII siècle au moins, avant d'arriver en Occident où le manuscrit le plus ancien date du Xe $\mathrm{X}^{\mathrm{e}}$ sècle $^{22}$. Elle se diffusa largement à partir du XIII ${ }^{\mathrm{e}}$ siècle : onze versions en vers et en prose, datant de la fin du XII ${ }^{e}$ au XV siècle, nous sont parvenues $^{23}$. La vie d'Eustache est également racontée dans la Légende dorée ${ }^{24}$. Placide était un général romain couronné de succès sous le règne de Trajan, marié et père de deux enfants. Au cours d'une chasse, il poursuit un grand cerf et se trouva isolé de ses compagnons. Soudain, l'animal se tourna vers lui et lui parla, une image du Christ entre les bois. C'était la voix de Dieu qui lui commandait de se convertir et de se faire baptiser avec sa famille. Le soir même, l'évêque lui donna le nom d'Eustache et à sa femme celui de Théopiste. Lorsqu'il retourna voir le cerf, il apprit qu'il devrait traverser de nombreuses épreuves pour prouver sa foi. Eustache et sa famille, comme Job, perdirent tous leurs biens. Leurs domestiques et leurs animaux moururent et le reste leur fut volé. Ils s'enfuirent en Égypte par la mer, mais le capitaine du bateau voulut garder Théopiste en paiement et débarqua Eustache et ses fils. Devant une rivière, Eustache décida de faire traverser ses fils un par un. Alors qu'il retournait chercher le deuxième enfant, il se trouva impuissant au milieu du cours d'eau, voyant ses fils emportés l'un par un lion, l'autre par un loup. Eustache passa alors quinze ans à travailler aux champs, convaincu qu'il avait perdu toute sa famille. Ses fils avaient pourtant été recueillis séparément par des paysans et des bergers. À Rome, l'empereur Trajan fit chercher son brillant général Placide. Une fois ses fonctions militaires recouvrées, Eustache retrouva ses fils enrôlés, réunis par chance dans l'auberge où avait travaillé sa femme toutes ces années après avoir été libérée, l'honneur sauf, par le capitaine du bateau. De retour à Rome, ses titres et ses possessions recouvrés, la famille refusa d'adorer les idoles et d'abjurer sa foi. L'empereur Adrien la jeta dans la fosse au lion, mais elle survécut miraculeusement. Elle subit alors le martyre dans un taureau d'airain rougi au feu mais les corps, intacts, furent enterrés dignement par les chrétiens. 
Figure 15

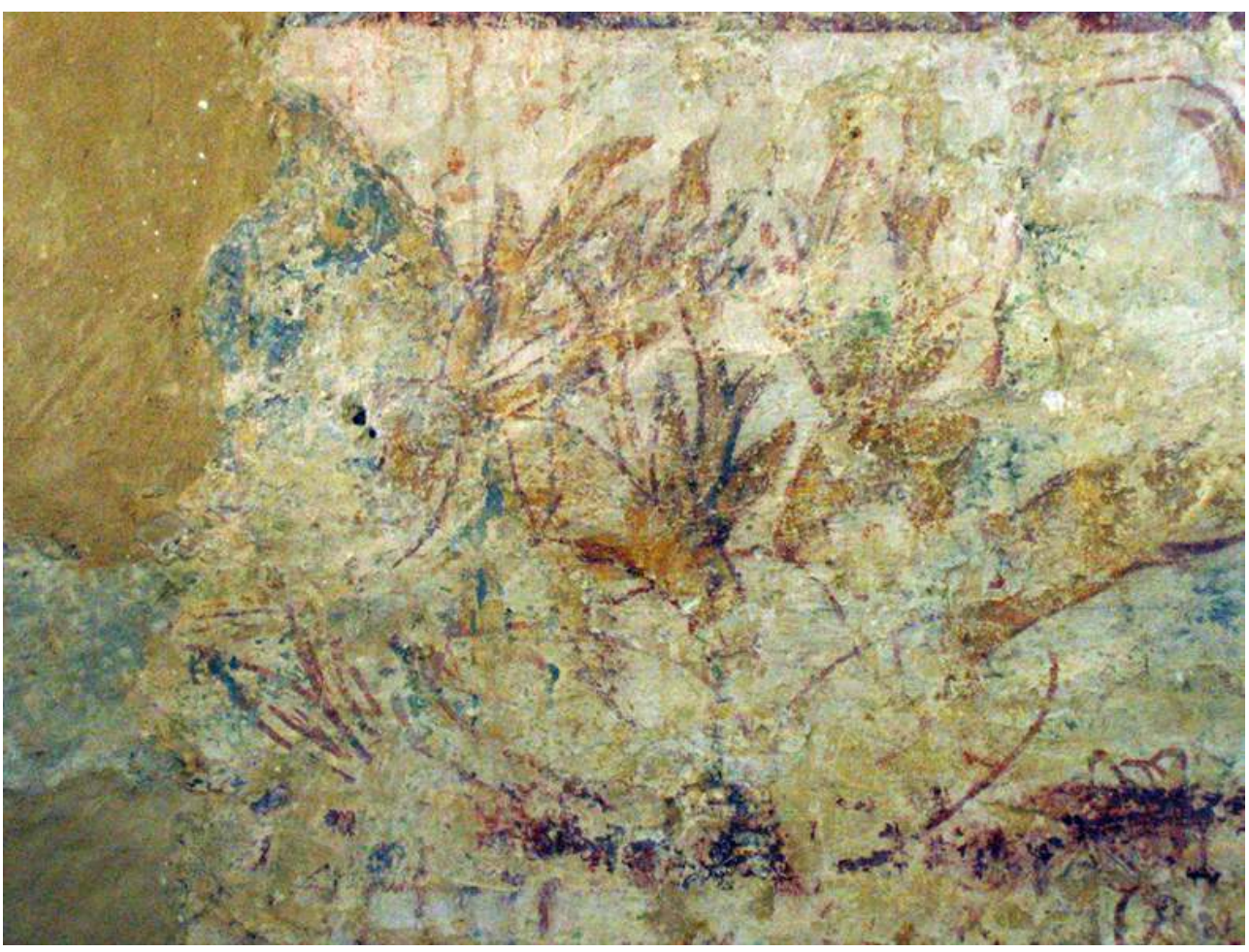

Mur ouest, $2^{\mathrm{e}}$ registre : une horde de cerfs, septembre 2005.

Phot. Victoir, G. (c) G. Victoir. 
Figure 16

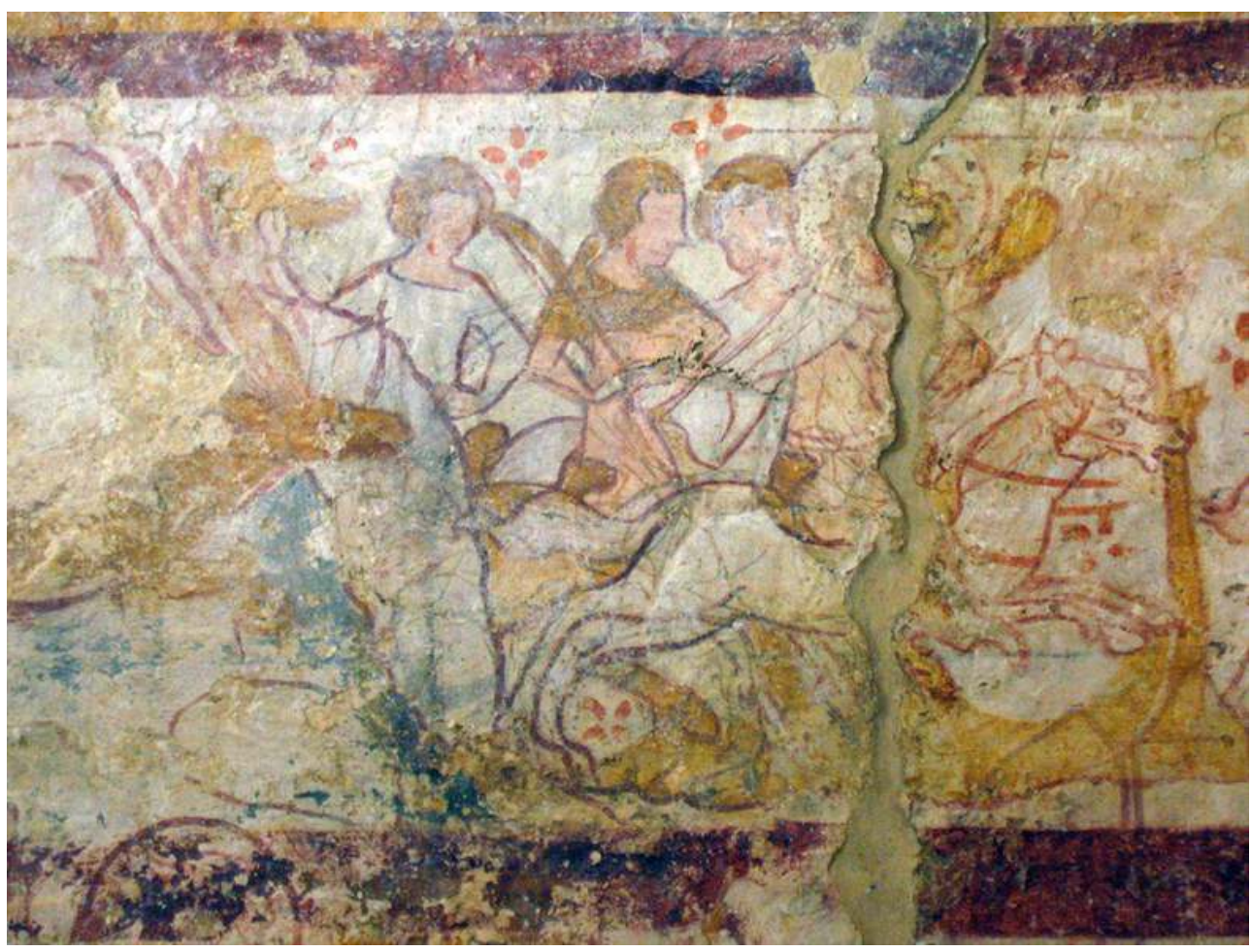

Mur ouest, $2^{\mathrm{e}}$ registre : un groupe de chasseurs, saint Eustache sonnant l'olifant, septembre 2005. Phot. Victoir, G. (c) G. Victoir.

\section{Figure 17}

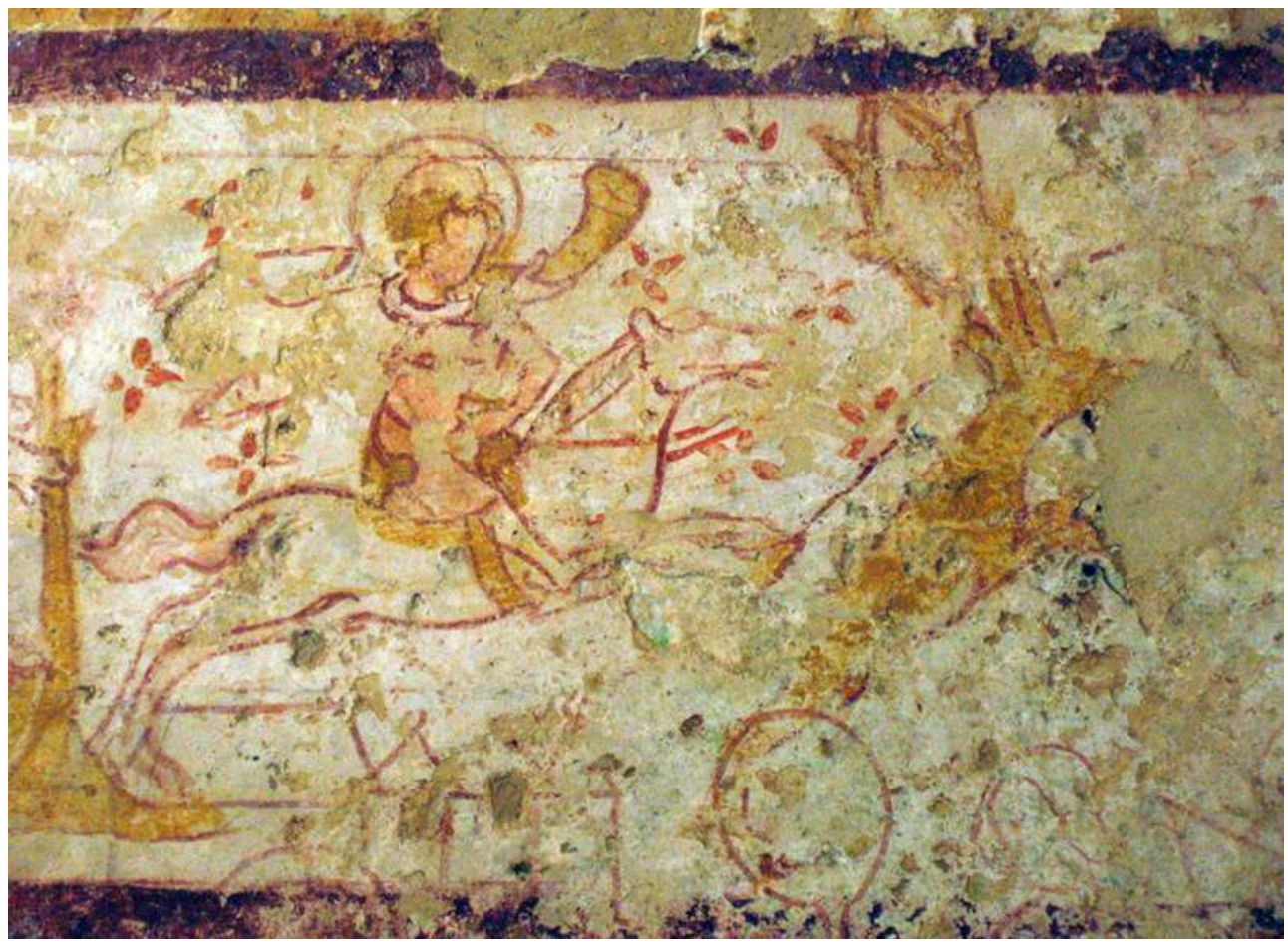

Mur ouest, $2^{\mathrm{e}}$ registre : saint Eustache poursuivant un grand cerf, septembre 2005.

Phot. Victoir, G. @ G. Victoir. 
Figure 18

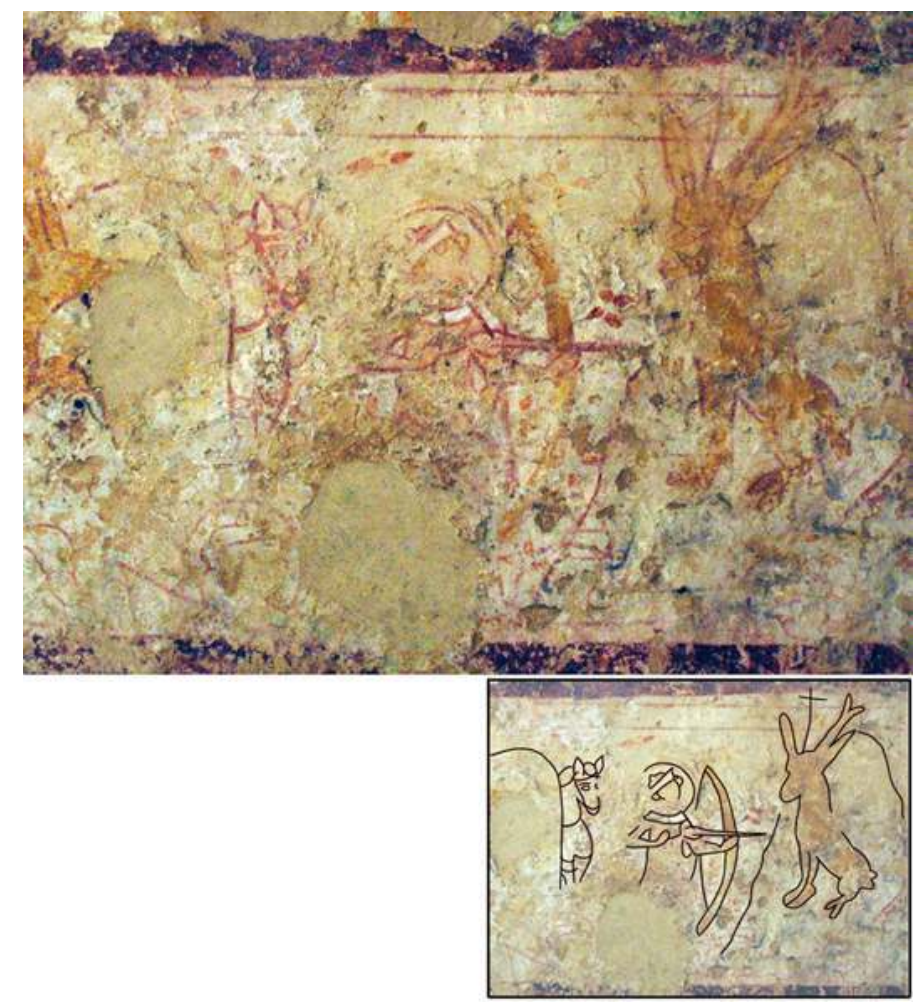

Mur ouest, $2^{\mathrm{e}}$ registre : saint Eustache descendu de son cheval, la flèche de son arc pointée vers le cerf assis ; une croix apparaît entre les bois de l'animal, septembre 2005.

Phot. Victoir, G. @ G. Victoir.

Le succès de cette histoire, d'abord littéraire, donna lieu à de nombreuses images. Les cycles conservés, exécutés en Occident entre le $\mathrm{XI}^{\mathrm{e}}$ et le XIV ${ }^{\mathrm{e}}$ siècle, ont récemment été inventoriés ${ }^{25}$. Seules deux autres peintures murales nous sont parvenues, en Italie (Pomposa) et à Montpellier (maison des Carcassonne). Si l'on excepte les vitraux de Chartres, du Mans et de Tours, tous trois plus vieux d'un siècle, le cycle de Lachapelle est le plus long. Il se développe d'ouest en est, de haut en bas sur le deuxième et le troisième registre, en de nombreuses scènes dont une douzaine est lisible. Sur le deuxième registre, on trouve sur le mur occidental : une portion de mur illisible; plusieurs cerfs dont un s'échappe de la horde (fig. $\left.\mathbf{n}^{\circ} \mathbf{1 5}\right)$; Placide sonnant l'olifant et trois autres chasseurs à cheval (fig. $\mathbf{n}^{\circ} \mathbf{1 6}$ ) ; Placide chevauchant seul, toujours sonnant l'olifant, derrière le cerf (fig. $\left.\mathbf{n}^{\circ} \mathbf{1 7}\right)$; et Placide à pied, son cheval derrière lui, pointant son arc tendu en direction du cerf qui lui fait face, une croix entre les bois (fig. $\mathbf{n}^{\circ} \mathbf{1 8}$ ). 


\section{Figure 19}

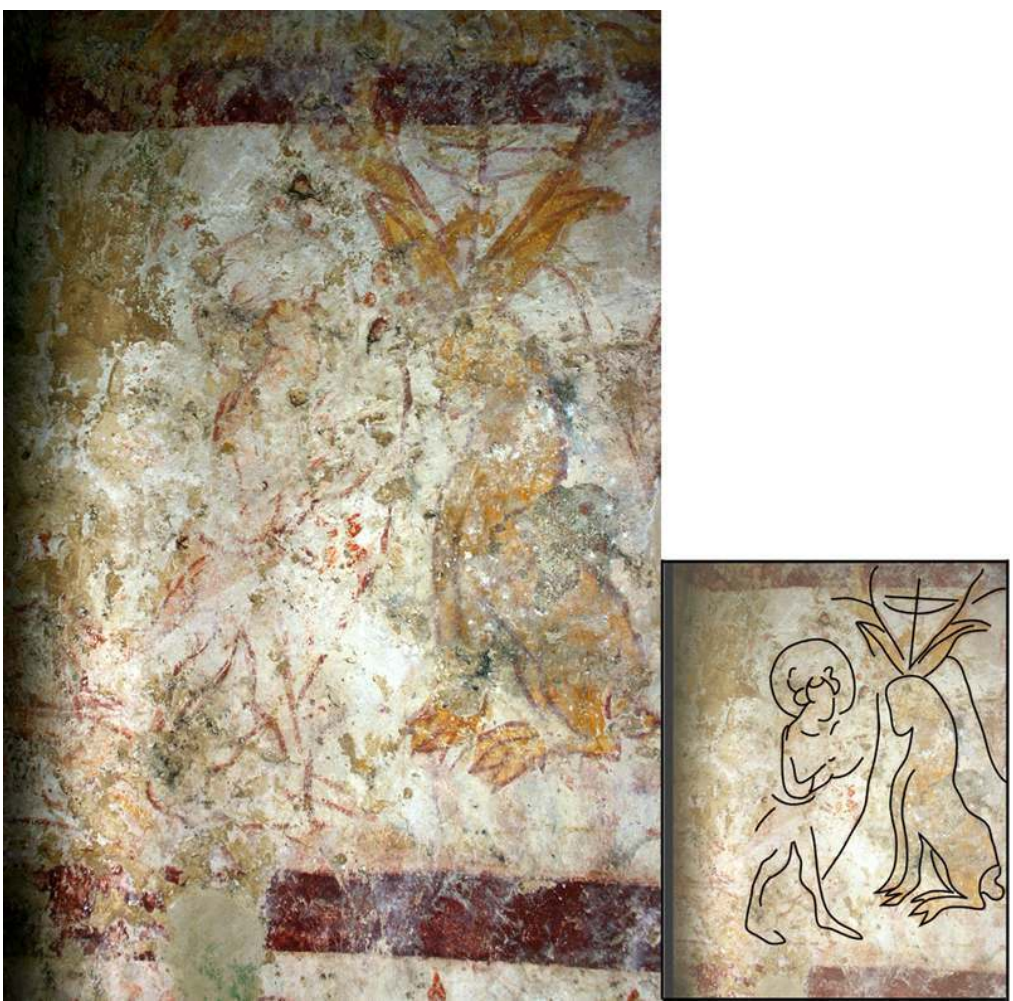

Mur nord, $2^{\mathrm{e}}$ registre : saint Eustache debout, conversant avec le cerf assis, la croix entre les bois, mai 2007.

Phot. Victoir, G. () G. Victoir. 
Figure 20

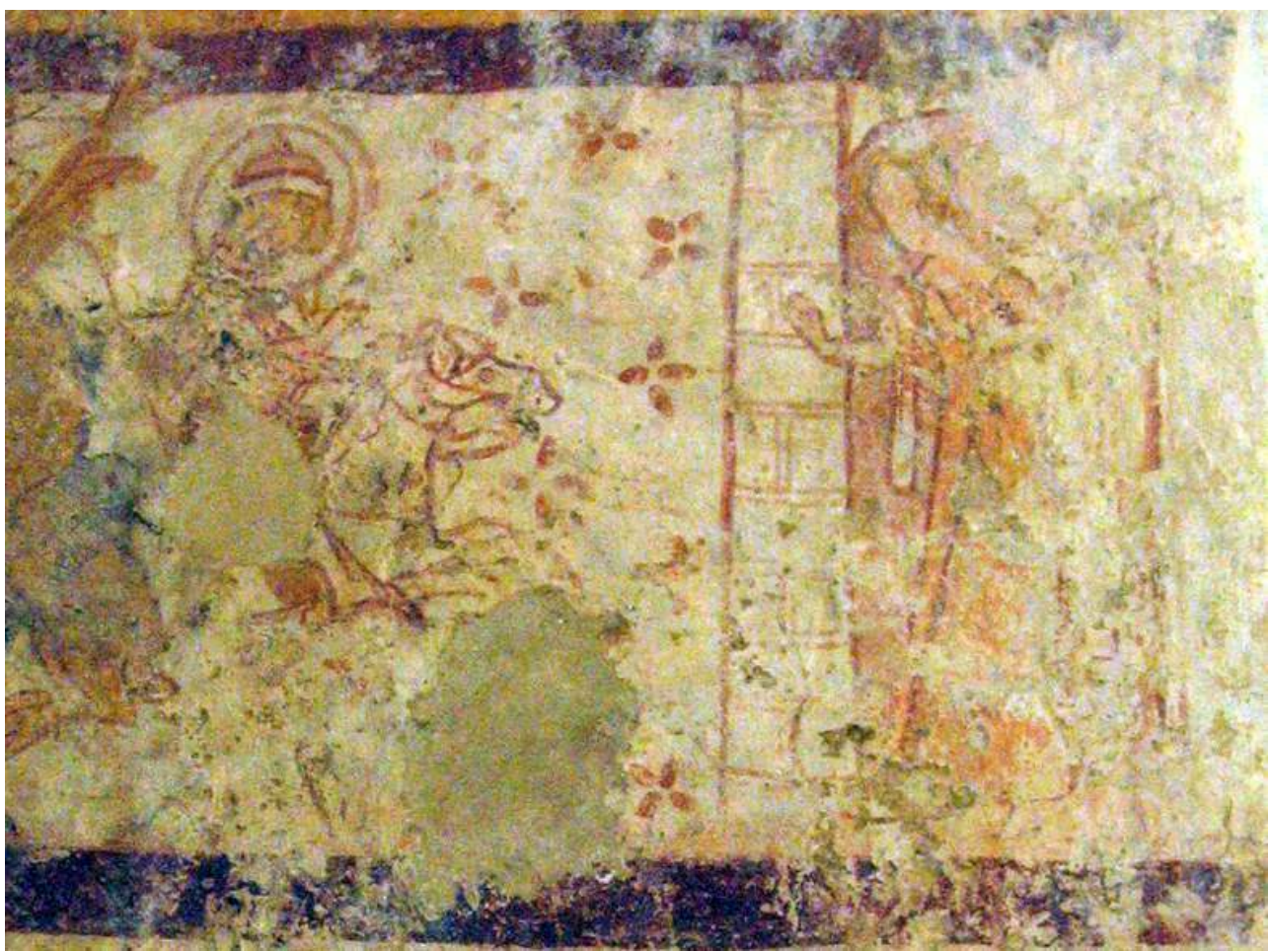

Mur nord, $2^{\mathrm{e}}$ registre : saint Eustache revenant au galop vers sa femme, qui l'attend sur le pas de la porte, septembre 2005

Phot. Victoir, G. @ G. Victoir.

\section{Figure 21}

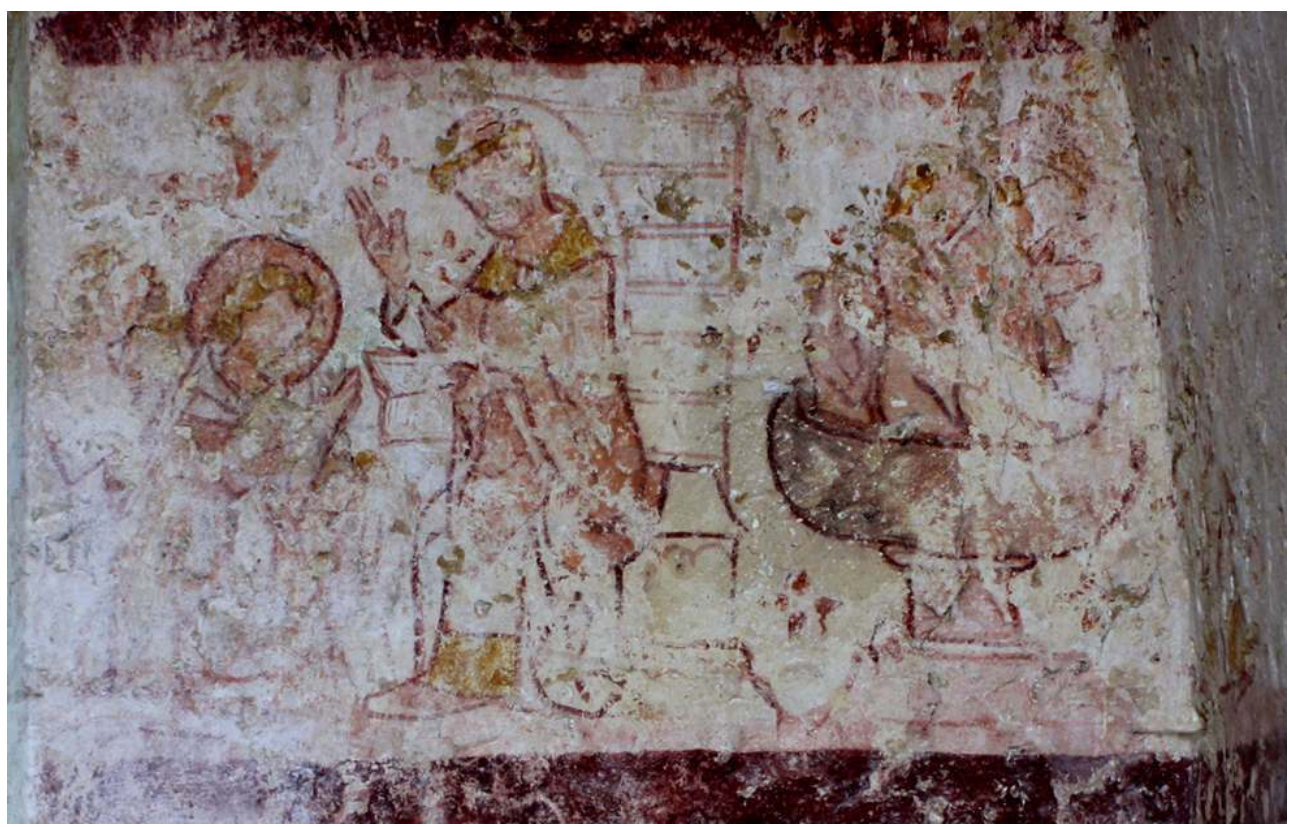

Mur nord, $2^{\mathrm{e}}$ registre : à gauche, saint Eustache et sa femme reçoivent du prêtre les enseignements chrétiens ; à droite, ils se font baptiser avec leurs enfants dans des grands fonts baptismaux, mai 2012.

Phot. Victoir, G. () G. Victoir. 
Figure 22

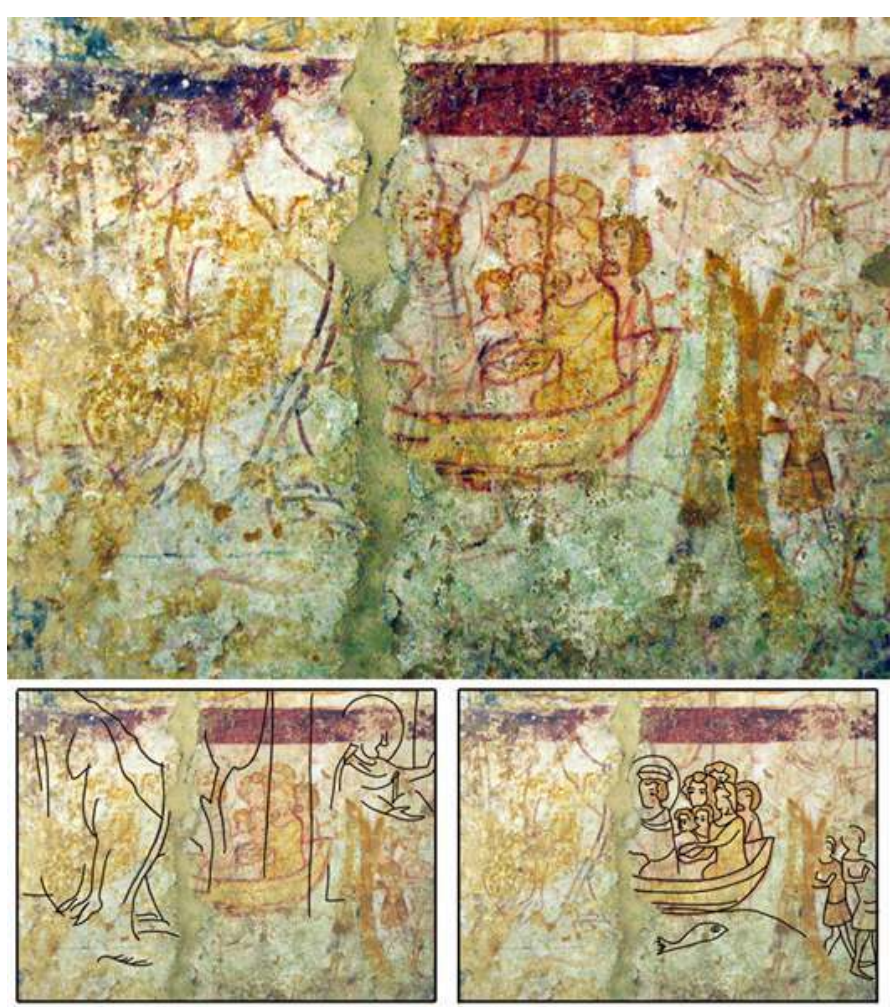

Mur ouest, $3^{\text {e }}$ registre : la famille fuit en Égypte sur un bateau. Le dessin préparatoire du premier projet (à gauche), de plus grandes dimensions, est visible sous le décor définitif (à droite), septembre 2005.

Phot. Victoir, G. @ G. Victoir.

11 La séquence continue sur le mur nord où Eustache debout, dialogue avec le cerf crucifère (fig. $\left.\mathbf{n}^{\circ} 19\right)$; Placide rentre à cheval chez lui, où sa femme l'attend à la porte (fig. $\left.\mathbf{n}^{\circ} \mathbf{2 0}\right)$; Placide et sa femme agenouillés devant un prêtre qui les bénit (fig. $\mathbf{n}^{\circ} \mathbf{2 1}$ ); et la famille dans des fonts (voir fig. $n^{\circ} 21$ ). Le prêtre les baptisant était peint sur le mur oriental mais il n'en reste que les pieds. Le cours de l'histoire reprend sur le troisième registre du mur occidental : après une scène illisible, la famille est dans un bateau (fig. $\mathbf{n}^{\circ} \mathbf{2 2}$ ); Eustache et ses fils sont débarqués (voir fig. $n^{\circ} 22$ ) ; et Eustache est au milieu de la rivière, tandis que ses fils sont emportés de part et d'autre par une bête sauvage et simultanément sauvés (fig. $\mathbf{n}^{\circ}$ 23) : un homme frappe un lion avec une bêche (la scène dépasse sur le mur nord) (fig. $\mathbf{n}^{\circ} \mathbf{2 4}$ ), tandis que son équivalent a presque entièrement disparu. Sur le mur nord, les enfants sont emmenés par deux hommes vers le village (fig. $\mathbf{n}^{\circ} \mathbf{2 5}$ ) ; et Eustache, après être passé par une porte, accueille les émissaires de Trajan, un outil agricole sur l'épaule (fig. $\mathbf{n}^{\circ} \mathbf{2 6}$ ). La fin de l'histoire jusqu'au martyre devait se trouver sur le mur oriental. Un texte aujourd'hui illisible était peint en blanc sur la bande rouge de séparation des registres. 
Figure 23

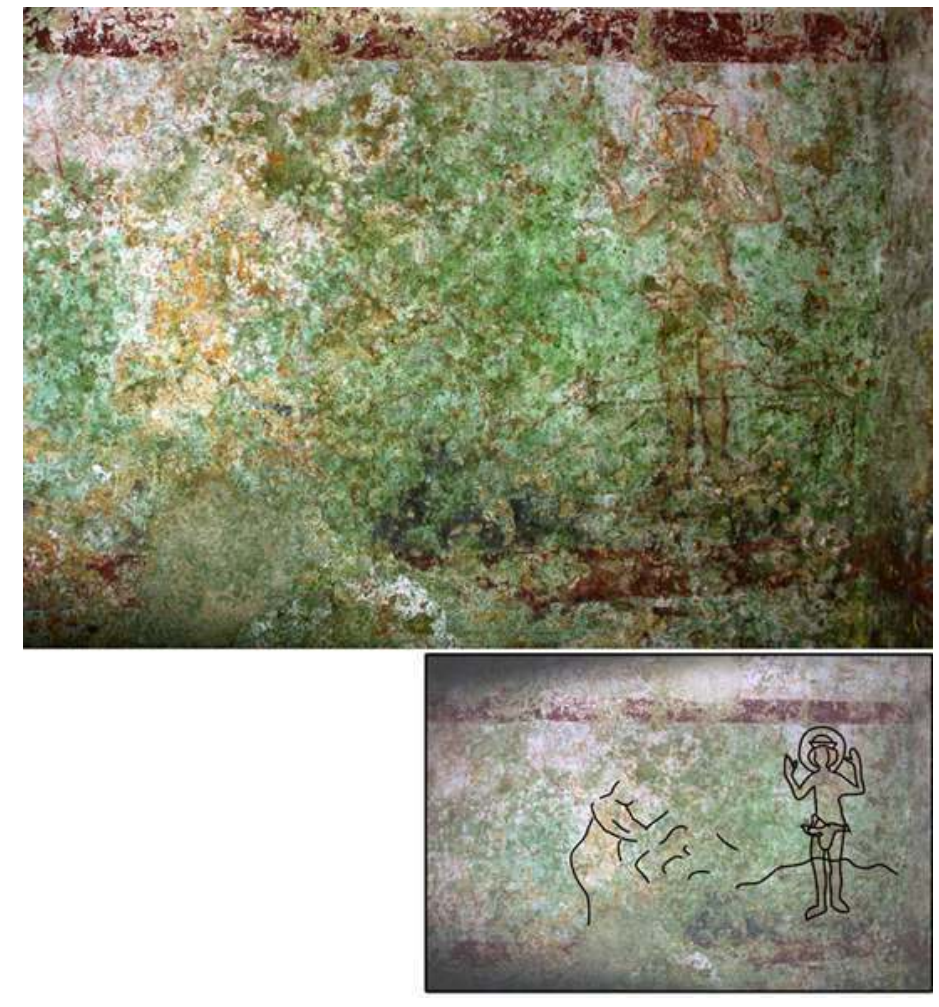

Mur ouest, $3^{\mathrm{e}}$ registre : saint Eustache au milieu de la rivière, les bras levés de désespoir voit ses enfants emportés par des bêtes sauvages (celle à sa droite est très effacée, celle à sa gauche est sur le mur nord, voir figure 23), mai 2007.

Phot. Victoir, G. (c) G. Victoir. 
Figure 24

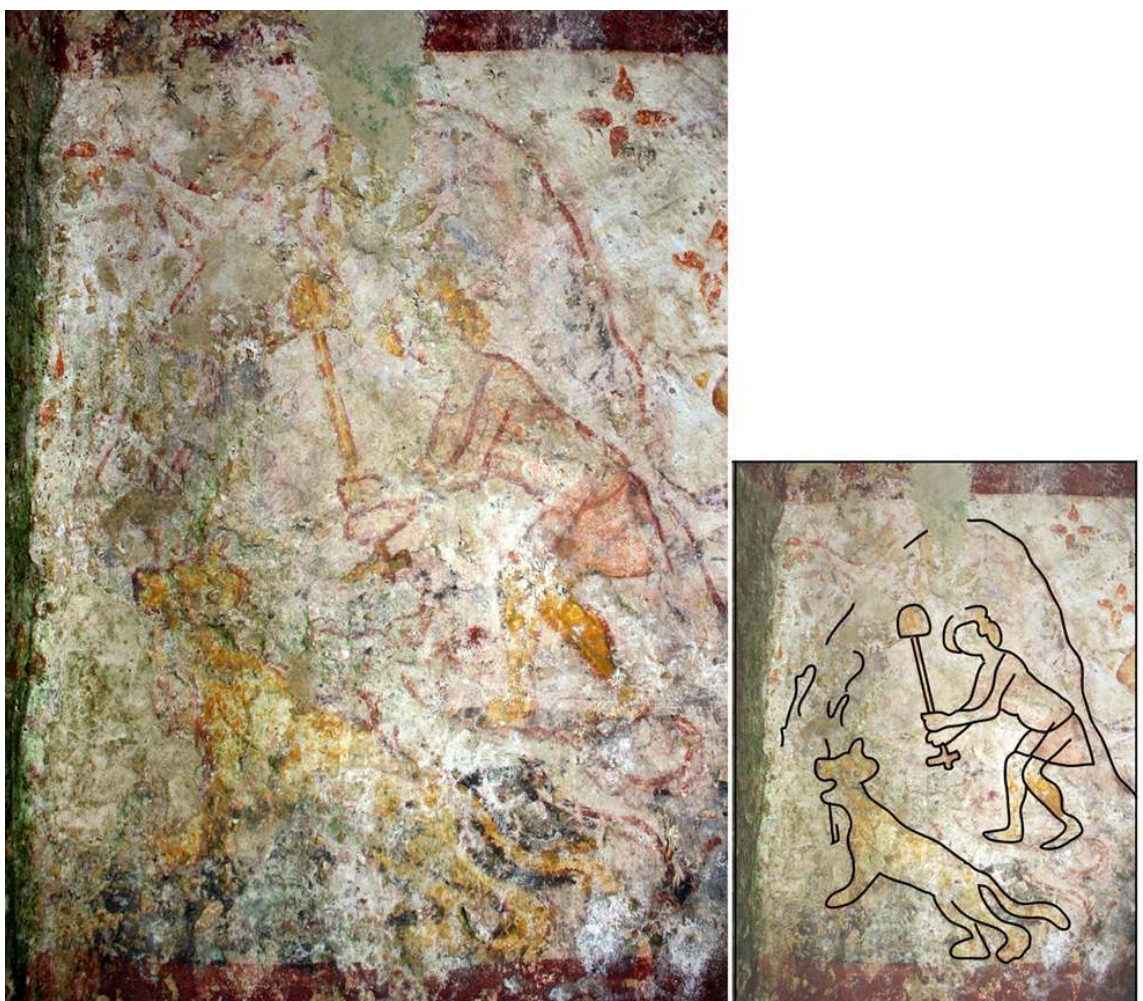

Mur nord, $3^{e}$ registre : un enfant de saint Eustache est emporté par un lion et sauvé par un homme qui frappe l'animal de sa bêche, mai 2007.

Phot. Victoir, G. () G. Victoir. 


\section{Figure 25}

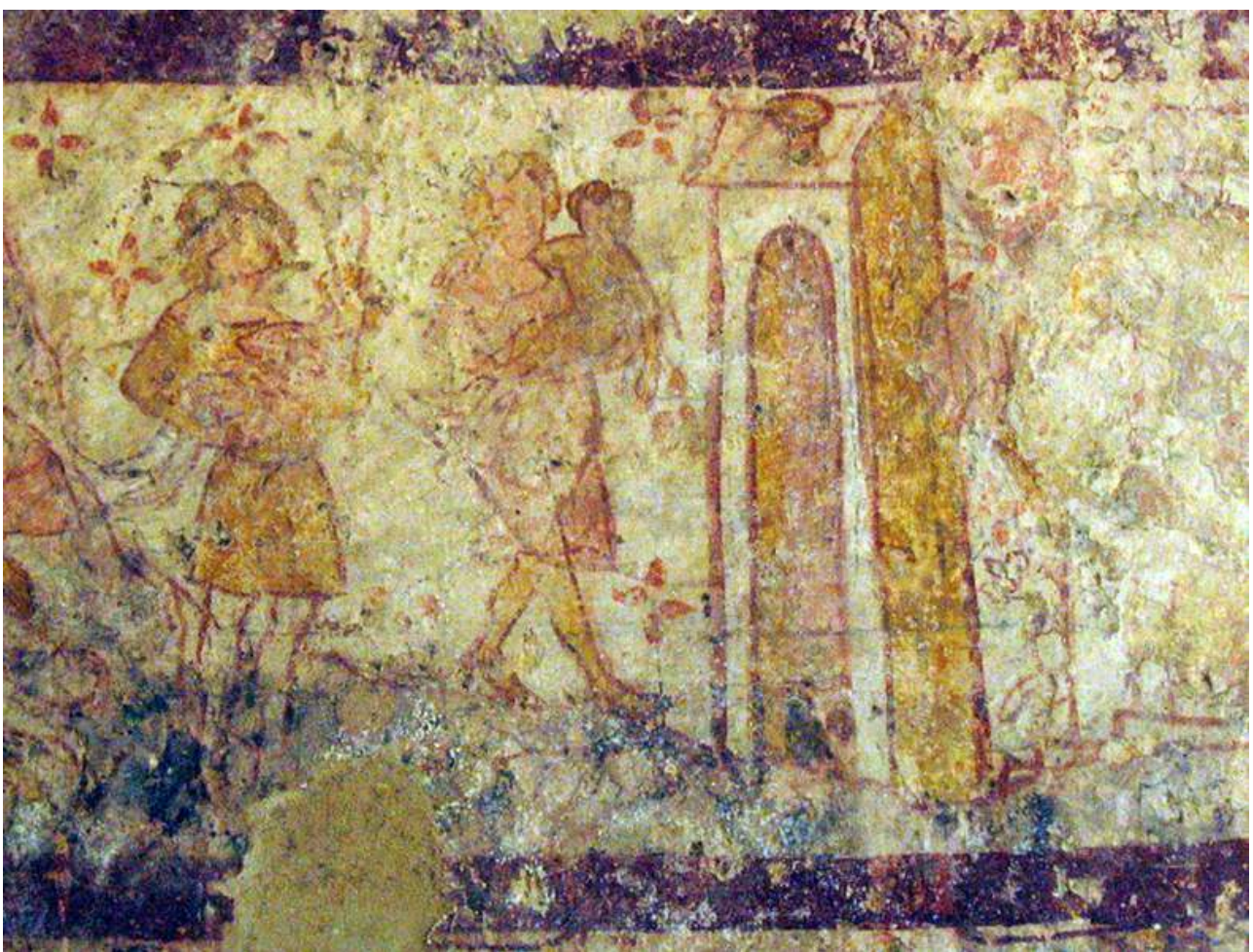

Mur nord, $3^{e}$ registre : les enfants sauvés sont amenés au village par les hommes (remarquez le chien à la porte de la deuxième maison), septembre 2005.

Phot. Victoir, G. (c) G. Victoir. 


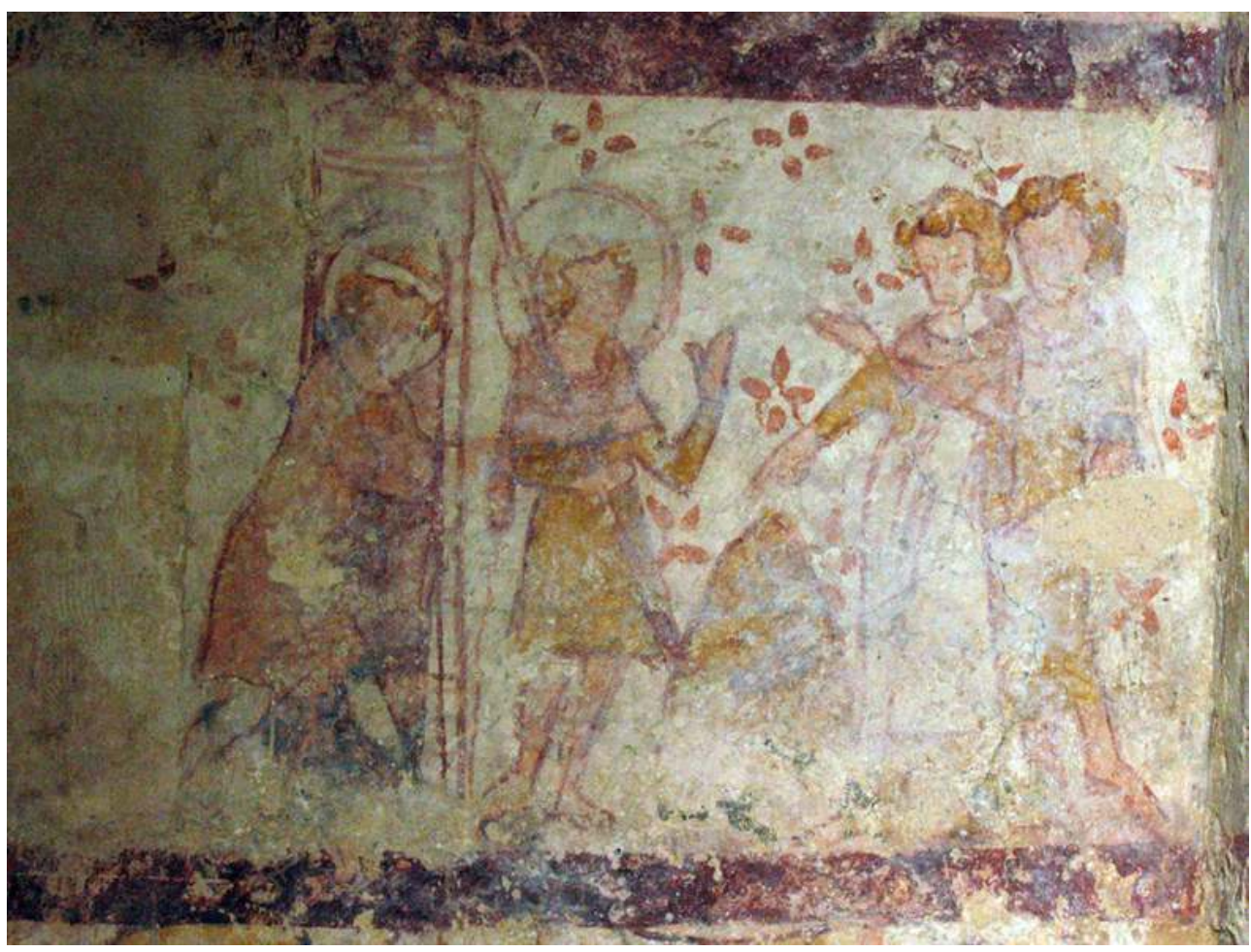

Mur nord, $3^{e}$ registre : saint Eustache passe à travers une porte, puis accueille, un outil agricole sur l'épaule, les hommes de Trajan qui le cherchent, septembre 2005.

Phot. Victoir, G. ( ) G. Victoir.

Le cycle comprend à la fois les scènes habituelles de la légende du saint et d'autres scènes très rares, voire uniques. Ainsi, la chasse est tout à fait caractéristique. On peut citer l'image très connue de la cathédrale de Chartres http://www.medievalart.org.uk/ Chartres/43_pages/Chartres_Bay43_Panel03.htm ${ }^{26}$ et, plus proche chronologiquement, un coffret parisien en ivoire, exécuté vers 1325-1350, anciennement dans la collection de Hever Castle et aujourd'hui dans une collection privée (fig. $\mathbf{n}^{\circ}{ }^{27}$ ), dénommé ci-après le coffret d'Eustache ${ }^{27}$. En revanche, une caractéristique notable de la peinture murale est la division de cet épisode en trois moments successifs : la horde de cerfs (probablement précédée sur la gauche par des chasseurs), le groupe de chasseurs, puis Eustache chassant seul le grand cerf (voir fig. n¹5-17). Aucun des cycles conservés ne présente un traitement aussi généreux de ce thème ${ }^{28}$. De la même façon, la fragmentation de la scène de la vision est unique : Eustache menace d'abord le cerf de son arc, puis semble discuter avec lui (voir fig. n¹8-19). En outre, le cerf n'est jamais représenté assis et Eustache n'est jamais debout, mais s'agenouille ailleurs devant l'animal, par exemple sur le retable éponyme de l'abbaye de Saint-Denis ${ }^{29}$. Saint Eustache n'est jamais représenté rentrant chez lui au galop (voir fig. $n^{\circ} 20$ ) mais il apparaît conversant avec sa femme juste après la vision sur le coffret d'Eustache (voir fig. $\left.n^{\circ} 27\right)^{30}$. De même, la conversion de Placide et de sa femme n'a pas d'équivalent (voir fig. $n^{\circ} 21$ ). Le baptême lui-même est en revanche un des épisodes les plus couramment représentés. Alors qu'Eustache est parfois seul dans les fonts, sa famille le rejoint souvent à partir du XIV ${ }^{e}$ siècle, par exemple dans un manuscrit du premier quart du XIV e siècle http://www.bl.uk/catalogues/illuminatedmanuscripts/ ILLUMINBig.ASP?size=big\&IllID=9852 ${ }^{31}$. 
Figure 27

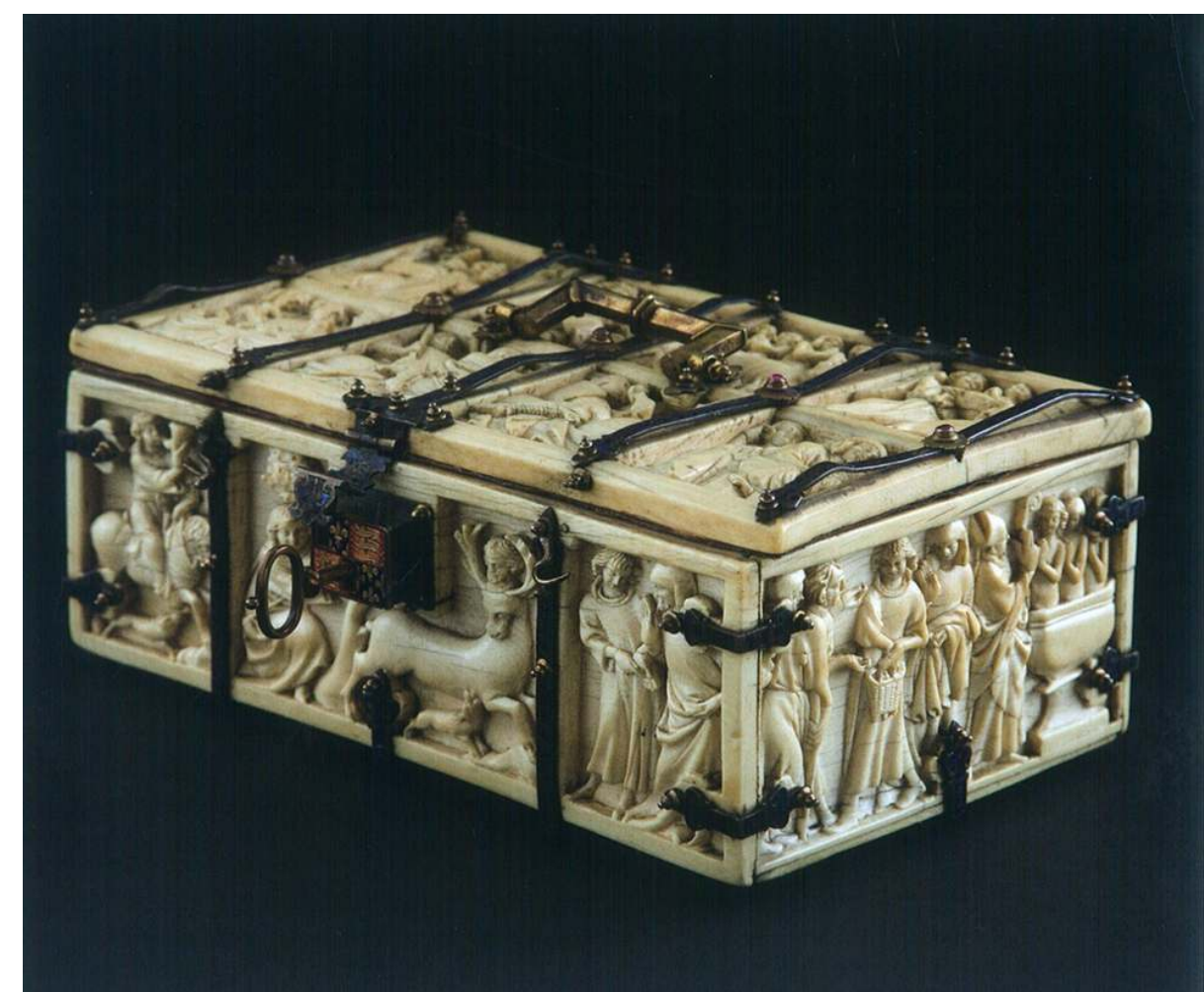

Coffret orné de la légende de saint Eustache (Paris, ca. 1325-1350, montants ajoutés au xviie siècle). Ivoire, montants en argent avec des grenats, $7,6 \times 18,1 \times 10,8 \mathrm{~cm}$. The Ronald's Lauder Collection, selection from the 3rd century BC to the 20Th Century, Germany, Austria, and France. Catalogue de l'exposition tenue à New York, Neue Galerie, du 27 oct. 2011 au 2 avril 2012.

collection privée.

Les scènes manquantes sur le mur oriental représentaient peut-être Eustache de retour dans la forêt, apprenant du cerf les épreuves qu'il devrait traverser, et le départ de sa famille. Sur le mur occidental, l'épisode du bateau était divisé en deux ou trois scènes (la partie gauche est perdue) (voir fig. $n^{\circ} 22$ ), solution comparable à celle adoptée à Chartres, bien que les scènes choisies soient différentes http://www.medievalart.org.uk/ Chartres/43_pages/Chartres_Bay43_key.htm, scènes 13, 14, 17. La scène qui suit est tout à fait caractéristique : Eustache, les pieds dans l'eau, les bras levés en signe de désespoir, voit ses enfants emmenés par des bêtes sauvages (voir fig. $n^{\circ} 23$ ), comme dans le manuscrit Egerton http://www.bl.uk/catalogues/illuminatedmanuscripts/ILLUMIN.ASP? Size=mid\&IllID=9853. Mais à Lachapelle-sous-Gerberoy, les enfants sont sauvés simultanément par un paysan et un berger, de part et d'autre d'Eustache (voir fig. $n^{\circ} 24$ ), traitement qui apparaît sporadiquement à partir du milieu du XIII ${ }^{\mathrm{e}}$ siècle, par exemple sur le retable de Saint-Denis et sur le coffret d'Eustache. La scène suivante, montrant les enfants amenés au village, est de nouveau unique, comme celle du saint passant par une porte (voir fig. $\mathrm{n}^{\circ} 25-26$ ). Enfin, la rencontre entre Eustache et les hommes de Trajan se retrouve dans l'iconographie du XIV ${ }^{\mathrm{e}}$ siècle, ainsi sur le coffret d'Eustache et le manuscrit Egerton http://www.bl.uk/catalogues/illuminatedmanuscripts/ILLUMIN.ASP? Size=mid\&IlliD=9854, où un champ de blé occupe l'arrière-plan plutôt que la meule de foin qui apparaît à Lachapelle-sous-Gerberoy (voir fig. $\left.n^{\circ} 26\right)^{32}$. 
14 Si les scènes sont aussi nombreuses que dans les vitraux, qui se prêtaient particulièrement bien à des cycles longs, il semble peu probable qu'il faille chercher là un modèle, car la composition ne reprend pas le découpage narratif des verrières connues. La présence de nombreuses scènes rares ou uniques permet de proposer une autre source : celle des Vies littéraires. Tout en adoptant les images les plus connues pour les scènes principales, le peintre a peut-être utilisé un texte pour étoffer le cycle, à moins qu'il n'ait eu à sa disposition les enluminures d'un manuscrit aujourd'hui perdu. La deuxième hypothèse semble plus probable, car le coffret d'Eustache offre des comparaisons pour certaines scènes rares (par exemple Eustache retrouvant sa femme après la vision) (voir fig. $\mathrm{n}^{\circ} 27$ ), ce qui suggère l'existence d'œuvres relevant d'une tradition iconographique dont peu de témoins nous seraient parvenus. En tout état de cause, la présence d'une inscription, malheureusement illisible, courant sous les scènes peintes confirme qu'un lien fort existait entre le cycle et une source textuelle.

Trois versions écrites de la vie d'Eustache seront utilisées ici pour comparer le texte et l'image : celle composée en français entre 1212 et 1217 par Pierre de Beauvais, sur la base d'un texte plus ancien provenant de l'abbaye de Saint-Denis, et deux Vies en anglonormand, la version de Cheltenham et celle de Guillaume de Ferrières, toutes deux datant $\mathrm{du} \mathrm{XIII}^{\mathrm{e}}$ siècle $^{33}$. Dans ces trois versions, Placide part chasser avec une grande suite ; il voit ensuite une horde de cerfs et suit le plus grand avec quelques compagnons, puis tout seul, car les autres chasseurs et chevaux sont épuisés ${ }^{34}$. C'est exactement cette structure en trois moments que l'on retrouve dans les premières scènes à Lachapelle-sous-Gerberoy (voir fig. $\mathrm{n}^{\circ} 15-17$ ). Alors qu'une image suffit pour évoquer cet épisode dans la plupart des autres exemples, une fidélité plus stricte au texte peut expliquer le début du cycle peint. De même, les images de la vision révèlent le développement du texte. Placide contemple d'abord le cerf perché sur un rocher, se demandant comment l'atteindre, avant de remarquer la croix entre ses bois : c'est la première des deux scènes peintes, montrant le héros tendant son arc vers l'animal, derrière lequel est sommairement dessinée une butte (voir fig. $\mathrm{n}^{\circ} 18$ ). Lorsqu'il entend le cerf parler, il tombe d'abord à la renverse, puis se redresse, l'écoute et se laisse convertir ${ }^{35}$. C'est la scène dépeinte sur le mur nord, où les deux personnages semblent discuter (voir fig. $\mathrm{n}^{\circ} 19$ ). La scène suivante, Placide chevauchant vers sa maison ne répond qu'à quelques vers dans les textes ${ }^{36}$ mais, d'une part, elle illustre le choix de Placide d'impliquer sa femme dans sa conversion et, d'autre part, elle cristallise un important moment de transition, celui du début du processus qui mènera la famille au salut (voir fig. $\left.\mathrm{n}^{\circ} 20\right)^{37}$. La division de la conversion en deux moments reflète elle aussi scrupuleusement les textes: la famille rend visite au prêtre qui lui enseigne les principes chrétiens, avant de la baptiser (voir fig. $\left.n^{\circ} 21\right)^{38}$. Les textes expliquent aussi la présence des paysans emmenant les enfants aux villages, scène inconnue dans la tradition iconographique (voir fig. $\left.n^{\circ} 25\right)^{39}$.

Il semble donc que le mode narratif littéraire ait été assez fidèlement transposé sur le mur. Il a en outre été traduit par des procédés picturaux qui facilitent la compréhension et contribuent à rendre l'histoire vivante et animée. Ainsi, les personnages sont le plus souvent tournés vers la droite du spectateur, indiquant le sens de lecture. L'action est souvent traduite par le mouvement, dans la scène de chasse mais aussi dans certaines scènes plus rares, qui créent une transition visuelle en présentant des personnages se déplaçant d'un lieu à un autre, comme Placide rentrant chez lui après la vision, les paysans amenant les enfants sauvés au village et Eustache se dirigeant vers les émissaires de Trajan. Nous sommes ainsi emmenés dans une histoire au rythme varié, parfois 
accéléré par le mouvement, parfois ralenti par la présence de scènes statiques, comme Placide et sa femme devant le prêtre avant le baptême.

\section{Eustache et les Fuvres de miséricorde}

Les deux scènes conservées du registre supérieur n'ont jamais été correctement identifiées (fig. $\mathbf{n}^{\circ} \mathbf{2 8}$ ) (fig. $\mathbf{n}^{\circ} \mathbf{2 9}$ ). P. Bonnet-Laborderie a proposé d'y voir des scènes de la vie de saint Benoît, en raison de l'inscription « saint Benet » ou « Benezet » en blanc sur le fond rouge de la scène d'enterrement; de plus le chapitre de Gerberoy, qui avait la collation du prêtre de Lachapelle, venait une fois par an en procession à la paroissiale le jour de la fête de saint Maure, disciple de saint Benoît ${ }^{40}$. Pourtant ces deux scènes, d' enterrement et de distribution d'aumônes, appartiennent aux Cuvres de miséricorde. Cellesci trouvent leur origine dans l'Évangile de Matthieu (25:35-36) où Jésus, annonçant le Jugement dernier, affirme que ceux qui se sont souciés du pauvre et du malheureux auront une place au royaume de Dieu. Il détaille six bonnes actions : nourrir l'affamé, abreuver l'assoiffé, accueillir l'étranger, vêtir les malheureux, soigner les malades et rendre visite aux prisonniers. Dès le troisième siècle, une septième œuvre, "enterrer les morts", fut ajoutée par Lactance, inspiré par Tobie $(1: 17)^{41}$. Le thème gagna en popularité $\mathrm{du} \mathrm{XII}^{\mathrm{e}}$ au XIVe siècle, dans un contexte de pauvreté croissante ${ }^{42}$. Les images des CEuvres de miséricorde étaient souvent associées au Jugement dernier selon l'Évangile de Matthieu, comme on le voit sur un vitrail de la cathédrale de Strasbourg ${ }^{43}$.

Figure 28

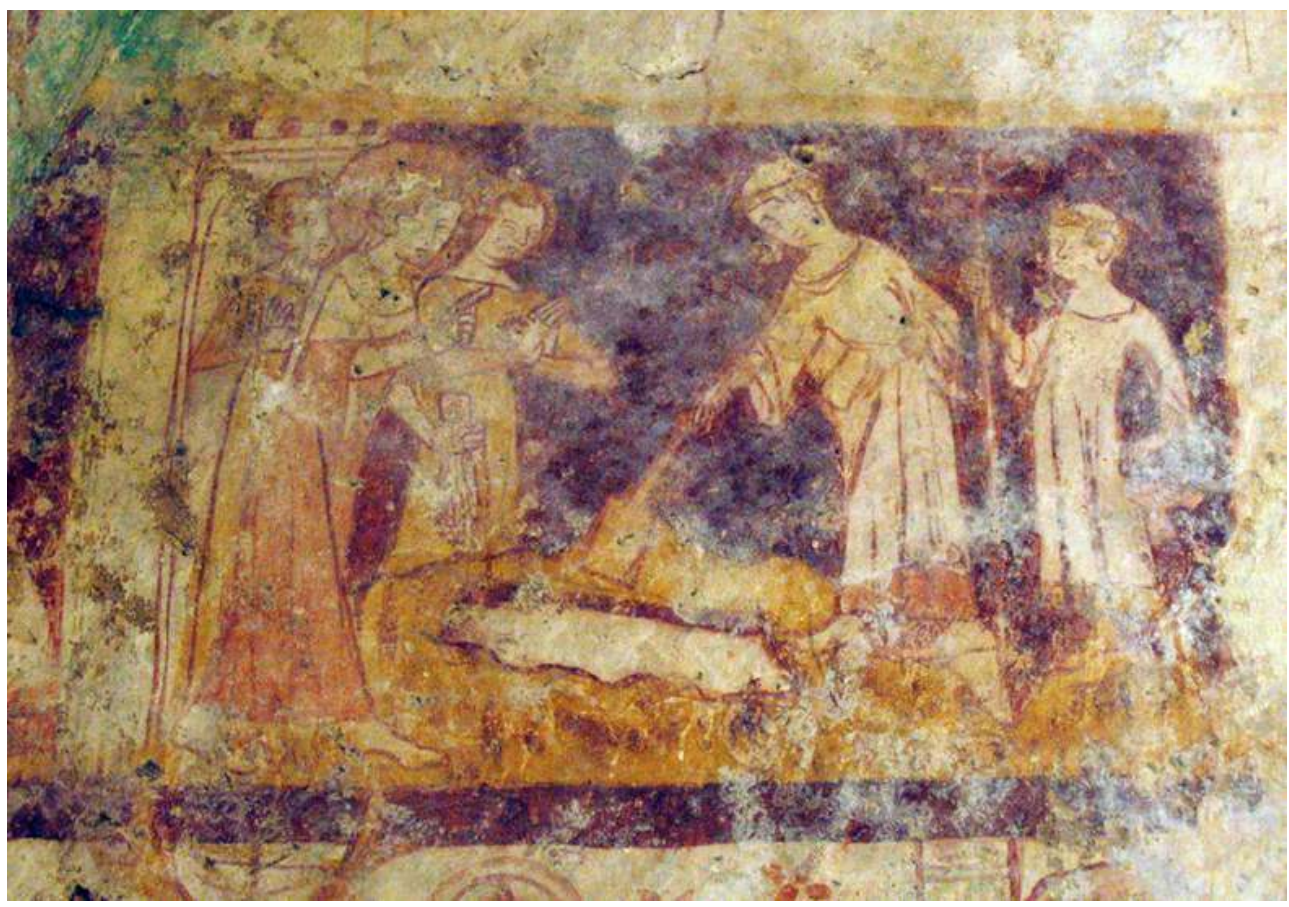

Mur nord, registre supérieur : saint Eustache et sa femme commandant l'enterrement d'un pauvre, septembre 2005

Phot. Victoir, G. @ G. Victoir. 


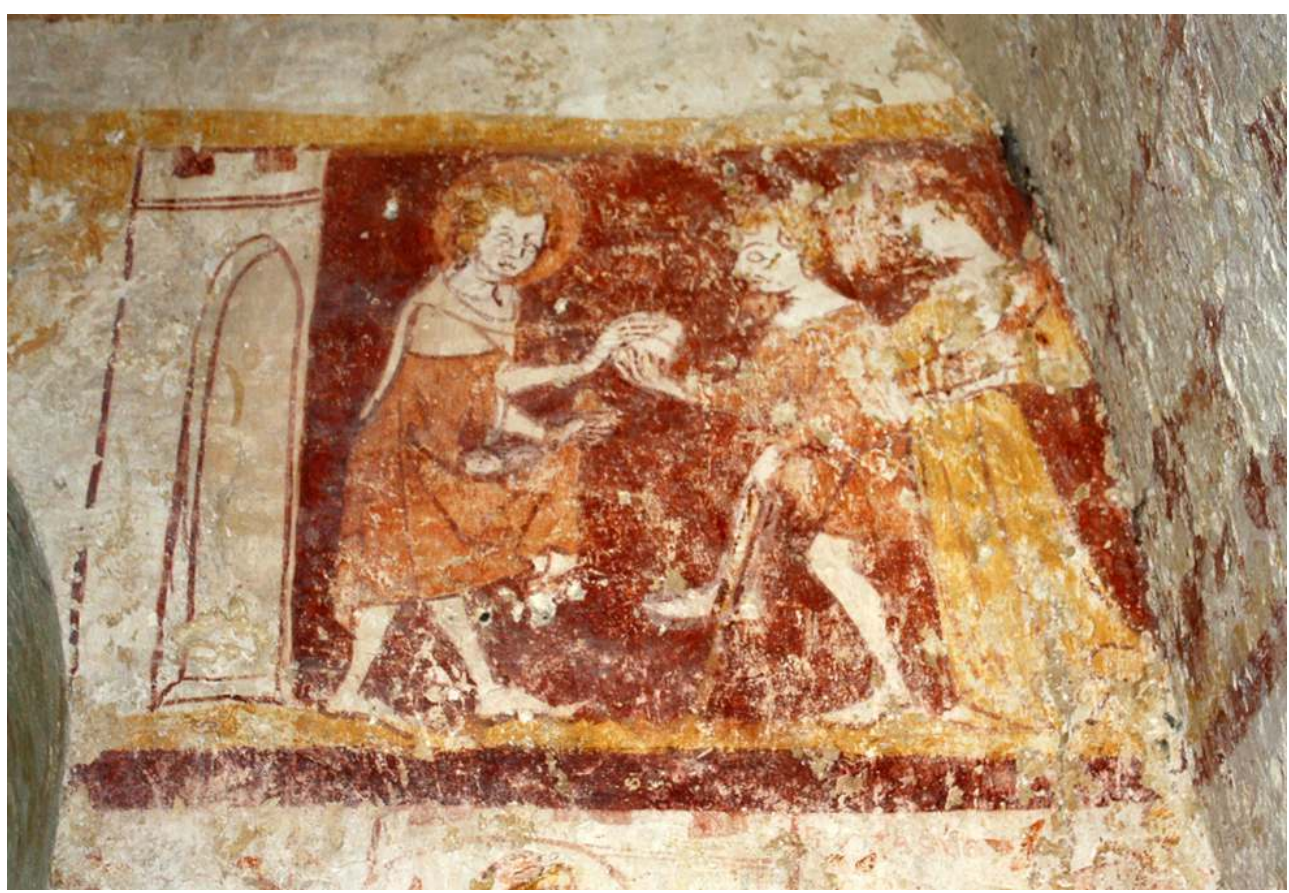

Mur nord, registre supérieur : saint Eustache et sa femme donnant l'aumône à un estropié, mai 2012. Phot. Victoir, G. @ G. Victoir.

18 À Lachapelle-sous-Gerberoy, les illustrations des Euvres de miséricorde présentent des caractéristiques dignes d'attention. L'homme qui ordonne l'enterrement est un noble, reconnaissable à sa coiffure, sa longue robe et la façon dont il tient ses gants, mais il est aussi saint, puisqu'il est nimbé (voir fig. $n^{\circ} 28$ ). Il est accompagné de deux personnages dont une femme. Les deux clercs préparant l'enterrement ne sont pas nimbés - une raison majeure de ne pas les identifier à saint Benoît et saint Maur. L'inscription est aujourd'hui en partie recouverte de sels et n'a pu être lue ${ }^{44}$. Dans la scène de l'aumône, le même saint en robe rouge et chaperon blanc est accompagné d'une femme vêtue de la même robe jaune (voir fig. $n^{\circ} 29$ ). Il ne s'agit donc pas de la représentation générique des Euvres de miséricorde, mais d'un saint et de sa femme les accomplissant, dans ce contexte certainement Eustache et Théopiste. Le reste du registre, sur les reins de la voûte, était probablement consacré à la série entière. Les Vies littéraires, encore une fois, donnent l'explication de ces images : la raison pour laquelle Dieu a choisi d'offrir la foi chrétienne à Eustache réside dans sa pratique régulière des CEuvres de miséricorde ${ }^{45}$. Alors que les Vies énumèrent les bonnes actions, la Légende dorée, plus synthétique, mentionne simplement que Placide était « très assidu dans les œuvres de miséricorde » et que sa femme était «miséricordieuse $»^{46}$. Le sujet revient plus tard dans le texte lorsque Dieu, parlant à Placide à travers le cerf, lui dit qu'il a reçu ses aumônes ${ }^{47}$, référence directe à l'Évangile de Matthieu (25:40) dans laquelle le Seigneur affirme que toute charité faite aux pauvres lui est faite personnellement. Le texte exprime donc clairement que Dieu considérait la bonne conduite de Placide et de sa femme comme la clé de leur salut. Pour l'homme médiéval, habitué aux sermons louant les CEuvres de miséricorde comme un moyen d'atteindre le paradis ${ }^{48}$, le texte des Vies ne présentait aucune ambiguïté.

Peu d'œuvres d'art ont traduit cet aspect essentiel de la vie d'Eustache, peut-être parce que, expression de la charité du couple plutôt qu'événement spécifique, il entrait 
difficilement dans un développement narratif. Pourtant, sur le coffret d'Eustache, la distribution d'aumônes à un infirme est insérée juste avant le baptême, comme s'il s'agissait de sa justification (voir fig. $n^{\circ} 27$ ). Ces remarques confirment que ce coffret relève de la même tradition iconographique que le cycle peint, tradition qui entretenait un lien fort avec un texte.

À Lachapelle-sous-Gerberoy, les Euvres de miséricorde ont été traitées séparément de la vie d'Eustache. D'une part, elles pouvaient être assimilées à la narration, puisqu'on y retrouvait les protagonistes, décrits comme dans les Vies littéraires avant leur conversion. D'autre part, placées sur le registre supérieur, juste au-dessous de l'assemblée de saints occupant le berceau brisé, et différenciées du reste du cycle par la couleur rouge du fond qu'elles partagent avec l'Annonciation au sommet du mur mord, elles étaient visuellement liées au divin. La série peut être lue comme un comportement exemplaire, un modèle, un guide des actions qu'un noble et sa femme doivent entreprendre pour suivre la volonté de Dieu et gagner une place au paradis. Le lien de causalité entre la charité et le salut de l'âme est exprimé sans ambiguïté dans les manuscrits du Breviari d'Amor : sept œuvres de miséricorde étaient suivies d'une vignette représentant l'âme de l'homme zélé emmenée par des anges, intitulée « la récompense de l'homme bon qui a accompli les œuvres de miséricorde » http://www.e-corpus.org/notices/100491/gallery/, image 1549.

21 À Lachapelle-sous-Gerberoy, la composition et le choix des couleurs équilibrent les deux niveaux de lecture du registre, le premier lié à la narration de la vie de saint Eustache, le second proposant le chemin à suivre pour gagner le ciel.

Quand les CEuvres de miséricorde fournissaient l'exemple de la charité, les aventures d'Eustache offraient un idéal de foi à toute épreuve, particulièrement adapté à l'aristocratie du milieu du XIV ${ }^{e}$ siècle. La perte de ses biens et de sa famille n'était pas un événement impossible pour un noble au Moyen Âge et suscitaient aisément l'émotion et l'empathie. Par ailleurs, la chasse d'Eustache fait écho à une des activités favorites de la noblesse, la chasse au cerf, divertissement qui lui était réservéso ${ }^{5}$. Ce thème était un décor apprécié dans les demeures nobles, tel le château du Vaudreuil, dont les peintures exécutées en 1349-1356 pour le roi Jean le Bon sont connues par des textes ${ }^{51}$. Un autre saint, Julien l'hospitalier, présente de nombreuses similitudes avec Eustache: laïc et marié, il aimait chasser et a connu de nombreuses épreuves. Un cycle de la vie de saint Julien peint dans une maison forte à Largny-sur-Automne (Aisne) est comparable à celui de saint Eustache à Lachapelle-sous-Gerberoy, il résulte aussi de la commande d'un noble peut-être assez modeste, même s'il s'agit d'une demeure plutôt que d'une chapelle ${ }^{52}$. Seul le début du cycle est préservé, mais on y retrouve la division d'un unique épisode de chasse en plusieurs scènes, comme à Lachapelle http://www.cg49.fr/culture/ peintures_murales/medias/pdf/geraldine_victoir.pdf, (voir fig. $\left.\mathbf{n}^{\circ} \mathbf{2}, \mathbf{n}^{\circ} \mathbf{4}\right)$.

\section{L'Annonciation}


Figure 30

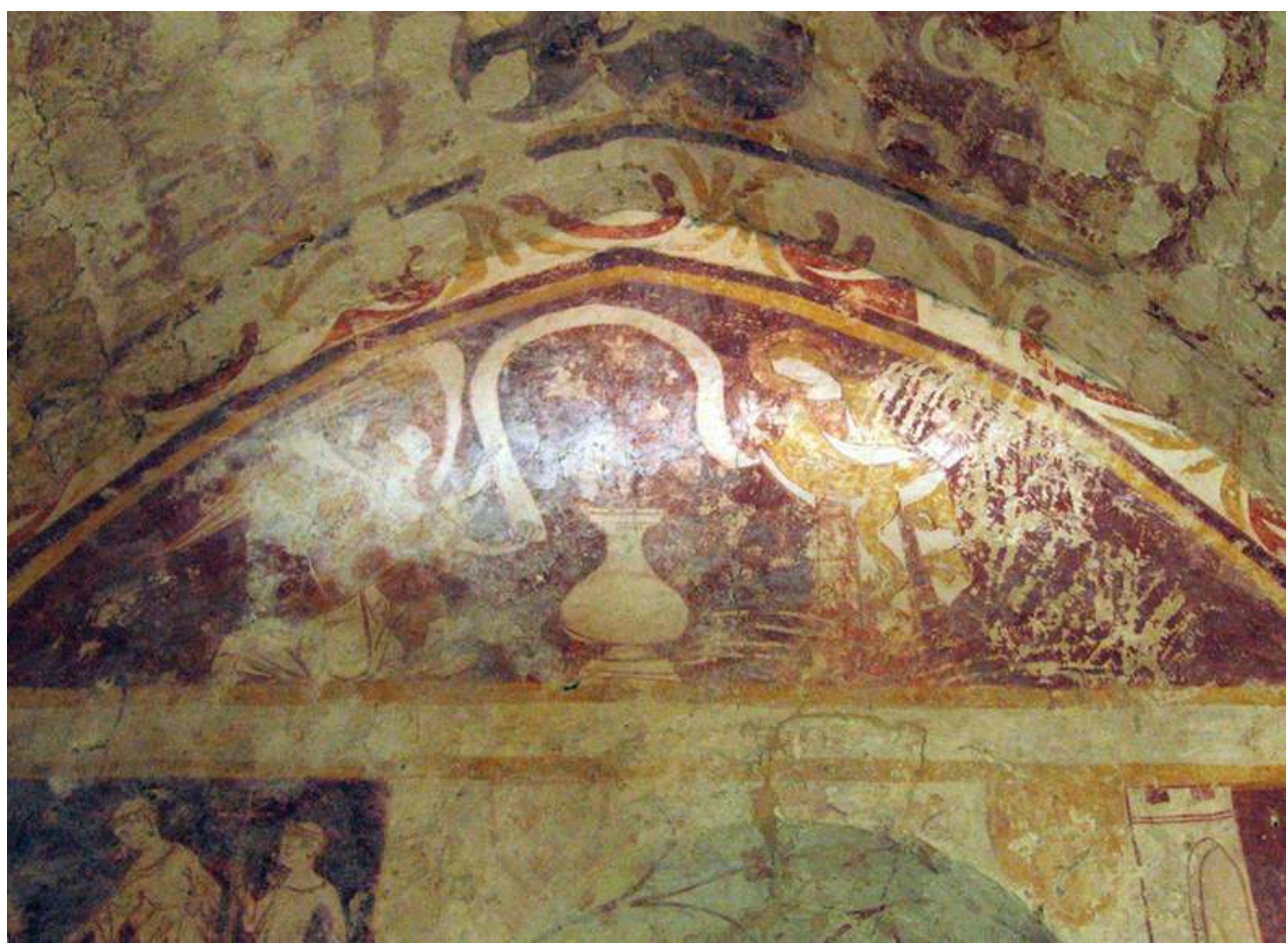

Mur nord, l'Annonciation, septembre 2005.

Phot. Victoir, G. (c) G. Victoir.

Une monumentale Annonciation est logée au sommet du mur nord (fig. $\mathbf{n}^{\circ} \mathbf{3 0}$ ). Gabriel, agenouillé, bénit la Vierge d'une main et tient de l'autre un long phylactère qui s'incurve vers elle. Séparée de l'ange par un vase de lis, la Vierge debout tient un livre et a un léger mouvement de recul. L'image témoigne de la connaissance de types iconographiques qui ont fait leur apparition dans les dernières années du XIII ${ }^{\mathrm{e}}$ siècle en Italie et quelques années plus tard en Europe septentrionale. Ainsi, le motif du lis, qui semble prendre sa source dans un texte de saint Bernard le comparant à la virginité de Marie (inviolabile castitatis lilium), apparut l'une des premières fois dans l'Annonciation de la mosaïque de Cavallini à Santa Maria de Trastevere dans les années 1290 http://it.wikipedia.org/wiki/ File:Pietro_Cavallini_013.jpg ${ }^{53}$, tandis qu'un vase de fleurs (génériques) était employé presque simultanément dans l'iconographie septentrionale ${ }^{54}$. Alors qu'auparavant la Vierge tenait généralement un fuseau, elle porte souvent un livre à partir de cette époque, peut-être sous l'influence d'écrits contemporains comme ceux du PseudoBonaventure, qui narrait qu'elle était en train de lire la prophétie d'Isaïe lorsqu'elle reçut la visite de Gabriel ${ }^{55}$. La position agenouillée de l'ange fit son apparition quelques années plus tard en Italie: la peinture de Giotto dans la chapelle Scrovegni de Padoue (ca .1303-1305) http://it.wikipedia.org/wiki/File:Giotto_-_Scrovegni_-_-14-__The_Angel_Gabriel_Sent_by_God.jpg est traditionnellement considérée comme le plus ancien exemple, là aussi sous l'influence d'écrits franciscains soulignant le respect exprimé par Gabriel, s'inclinant devant Marie ${ }^{56}$. Le motif ne pénétra qu'une vingtaine d'années plus tard en France : l'exemple à la fois le plus célèbre et le plus précoce est dans le Livre d'Heures de Jeanne d'Evreux, enluminé par Pucelle vers 1325-1328 http:// www.metmuseum.org/toah/works-of-art/54.1.257, qui atteste de la connaissance précise du peintre de la peinture siennoise, sans désaveu de ses racines septentrionales ${ }^{58}$. L'ange 
agenouillé fut par la suite progressivement adopté dans le nord, par exemple dans les Heures de Jeanne de Navarre enluminées par Jean le Noir (1336-1349) ${ }^{59}$ et sur le portail de la Vierge de la cathédrale de Meaux (1336-1345) ${ }^{60}$. L'Annonciation de la Lachapelle-sousGerberoy témoigne d'une connaissance de ces motifs italiens, qui sont peu à peu assimilés par l'art du nord de la France dans les années 1330. Le peintre de Lachapelle montre donc une attention particulière aux nouveautés de l'art figuratif contemporain, attitude déjà remarquée pour le registre inférieur. Néanmoins, comme à Meaux, la principale innovation italienne de l'époque, un cadre architectural utilisant la perspective, est absente. Alors qu'elle avait été assimilée par Pucelle grâce à une connaissance directe des œuvres siennoises, elle ne semble pas avoir intéressé la plupart des peintres et sculpteurs septentrionaux avant plusieurs décennies.

Au cours du deuxième quart du XIV siècle l'Ave maria tend à se généraliser en raison de sa présence dans les Heures de la Vierge, composante indispensable des livres d'heures, mais aussi de pratiques dévotionnelles telles que la récitation de l'Angelus, prière répondant chaque soir à l'appel de la cloche. En 1327, cette pratique fut associée à une indulgence par le pape Jean XXII. En examinant les inscriptions d'un grand nombre d' Annonciation du Moyen Âge, Van Dijk a montré que cette image était associée à la prière plutôt qu'au texte biblique. Alors que dans l'Évangile de Luc (1:28-29), la salutation commence par les mots Ave, gratia plena, le nom de Marie était inséré dans la prière : Ave Maria, gratia plena. C'est cette dernière formule que l'on trouve dans les images ${ }^{61}$. Le fidèle pouvait joindre ses louanges à celles de l'ange, une idée parfaitement illustrée par l' Annonciation des Heures de Jeanne d'Evreux http://www.metmuseum.org/toah/works-ofart/54.1.2: non seulement l'ange tient un phylactère avec les mots Ave Maria, mais la commanditaire, Jeanne d'Évreux, est représentée lisant agenouillée - probablement récitant la prière - dans l'initiale située juste en-dessous ${ }^{62}$. L'Annonciation était donc particulièrement bien adaptée à un destinataire laïc, par exemple dans les livres d'heures ou les chapelles privées. À Lachapelle-sous-Gerberoy, les dimensions et l'emplacement de l'Annonciation, excluant toute dimension narrative, plaident pour cette fonction d'image de dévotion, même si aucune inscription n'est visible sur le phylactère.

\section{Les commanditaires}

Des deux blasons peints dans les écoinçons de la baie nord, seul celui de gauche est lisible mais non identifié par les armoriaux publiés ; il semble blasonné d'hermine, et porte trois losanges (fig. $\left.\mathbf{n}^{0} \mathbf{3 1}\right)^{63}$. Une recherche dans les armoriaux publiés n'a pas permis de les identifier ${ }^{64}$. Les archives sont également silencieuses sur les commanditaires de la chapelle. En revanche, six textes datés de 1238 et 1241 ont trait à des ventes et donations de terres au chapitre de Saint-Pierre de Gerberoy par Johannes de Capella ${ }^{65}$. Une autre vente au chapitre par Adam de la Chapelle et sa femme eut lieu en $1270^{66}$. Pillet mentionne parmi les bienfaiteurs du chapitre au XIII ${ }^{e}$ siècle Guillaume de la Chapelle et ses quatre enfants (Jean, Nicolas, Aelidis et Pierre), ainsi qu'Aubert de la Chapelle, sans date ${ }^{67}$. Selon un mémoire manuscrit daté de 1684 , les seigneurs possédaient la dîme au $\mathrm{XIII}^{\mathrm{e}}$ siècle et le plus ancien titre mentionnant le curé de la Chapelle est de l'an 1238 . Ce curé est probablement Pierre de la Chapelle, fils de Guillaume de la Chapelle, chevalier ${ }^{68}$. Enfin, l'obituaire du XVII e siècle de l'église de Lachapelle, reconstitué par le prêtre après la destruction de l'original à partir de divers documents, mentione un Guillaume de la Chapelle, chevalier en 1215 et Jean de la Chapelle, qui vivait en $1638^{69}$. 
Figure 31

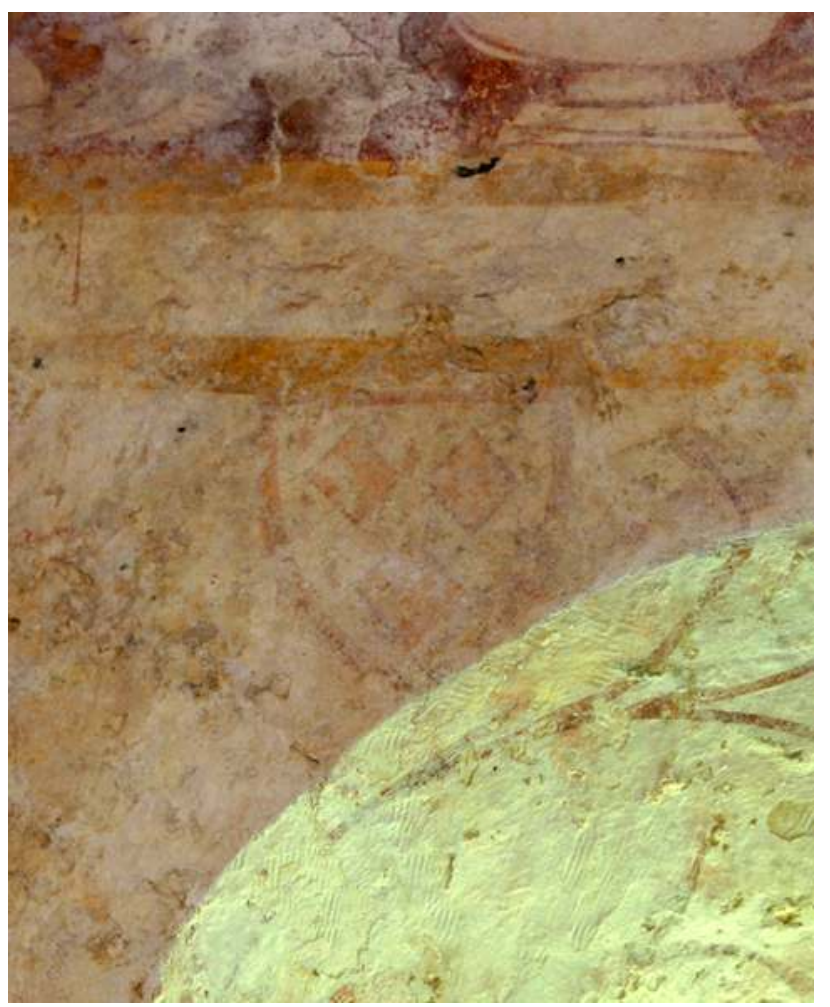

Mur nord, écoinçon de la baie : un blason, d'hermine à trois losanges, mai 2007

Phot. Victoir, G. (c) G. Victoir.

Bien qu'aucun de ces personnages n'ait vécu au XIV ${ }^{\mathrm{e}}$ siècle, on peut supposer que ce sont des membres de cette même famille qui construisirent et firent décorer la chapelle seigneuriale au XIV ${ }^{\mathrm{e}}$ siècle. La présence des deux blasons et l'iconographie permettent en tout cas de suggérer qu'il s'agissait d'un couple. On a vu que le cycle d'Eustache, homme laïc et marié, était tout à fait adapté dans ce contexte, particulièrement en raison de l'ampleur que prenait le registre du saint accomplissant les œuvres de miséricorde avec sa femme. En outre, les saintes sur les ébrasements de la baie nord laissent supposer une présence féminine.

\section{Conclusion}

Le décor de la chapelle seigneuriale à Lachapelle-sous-Gerberoy est un exemple éloquent $\mathrm{du}$ goût laïc au milieu du XIV siècle, même en l'absence d'identification des commanditaires. Son iconographie riche associe des saints, des saintes et une monumentale Annonciation, support visuel de la dévotion, à un cycle de la vie de saint Eustache exceptionnel à plusieurs titres. D'une ampleur sans égal, pour l'heure, en peinture murale, il combine des scènes rares et uniques à d'autres plus conventionnelles, selon des modalités qui laissent deviner un lien fort avec un texte. Surtout, l'inclusion unique d'un registre entier dédié aux œuvres de miséricorde de saint Eustache et de sa femme, qui se distingue par son fond rouge, traduit l'accent mis sur la portée morale et exemplaire du cycle. Ce message était d'autant mieux transmis qu'il était lié à des thèmes ludiques (la chasse) et capables d'émouvoir (la perte des enfants) susceptibles de susciter 
l'empathie chez un couple laïc. Le cycle proposait donc un exemple frappant, un guide de bonne conduite et de foi, en lien avec une vie pieuse et charitable potentiellement récompensée au jour du Jugement dernier.

\section{NOTES}

1. - GAULTIER, G. Sondages réalisés dans l'église de Lachapelle-sous-Gerberoy (Oise) du 12 novembre au 19 novembre 1990 (rapport inédit) ; BONNET-LABORDERIE, Pierrette. «Les peintures murales du XII ${ }^{\mathrm{i} e}$ - XIve siècle de l'Oise». Dans L'art gothique dans l'Oise et ses environs. Beauvais: GEMOB, 2001, p. 295-310. Malheureusement, les peintures se sont rapidement dégradées depuis. On observe des efflorescences de sel, de la mousse en partie basse et l'enduit semble infesté d'insectes.

2. - BONNET-LABORDERIE, Pierrette. "Les peintures murales du XII ${ }^{\mathrm{i} e}$ - XIv e siècle de l'Oise ". Dans L'art gothique dans l'Oise et ses environs. Beauvais : GEMOB, 2001, p. 301-305.

3. - Sur cette mode : NEWTON, Stella Mary. Fashion in the Age of the Black Prince. A Study of the Years 1340 - 1365. Woodbridge, Totowa (New Jersey) : Boydell Press, Rowman \& Littlefield, 1980, p. 9 ; BLANC, Odile. Parades et parures. L'invention du corps à la fin du Moyen Âge. Paris : Gallimard, 1997, p. 30-31; NETHERTON, Robin. "The Tippet: Accessory after the Fact?». Dans NETHERTON, Robin, OWEN-CROCKER, Gale. Medieval Clothing and Textile. Woodbridge: Boydell Press, 2005, p. $115-132$.

4. - Oxford, Bodleian Library, ms. Bod. 264. JAMES, M. R. The romance of Alexander. A collotype Facsimile of Ms. Bodley 264. Oxford : Clarendon Press, 1933.

5. - À ce sujet: GABORIT, Jean-René. «L'Art au temps de Philippe le Bel et de ses fils ». Dans GABORIT-CHOPIN, Danielle. L'art au temps des rois maudits : Philippe le Bel et ses fils, 1285-1328. Paris : Réunion des Musées nationaux, 1998, p. 26-31.

6. - GAULTIER, G. Sondages réalisés dans l'église de Lachapelle-sous-Gerberoy (Oise) du 12 novembre au 19 novembre 1990 (rapport inédit). Il contient une forte proportion d'argiles (environ $35 \%$ ).

7. - DESCHAMPS, Paul, THIBOUT, Marc. La peinture murale en France au début de l'époque gothique, de Philippe-Auguste à la fin du règne de Charles V (1180-1380). Paris : CNRS, 1963, p. 165 et pl. IX.

8. - TERRIER-FOURMY, Bérénice. Voir et croire: Peintures murales médiévales en Touraine. Tours : CLD, 2002, p. 106-107.

9. - SAUERLÄNDER, Willibald. Gothic Sculpture in France, 1140-1270. Londres : Thames and Hudson, 1972, p. 504-505.

10. - Conservée au V\&A Museum, Londres : CHRISTIE, A. G. I. English Medieval Embroidery. Oxford : Clarendon Press, 1938, n 75, p. 142-148, pl. XCVI. Thomas est parfois également représenté avec une épée. La Légende dorée précise qu'il a été tué par l'épée, mais qu'Isidore pense qu'il a été tué par une lance, présentant ainsi les deux versions au lecteur: VORAGINE, Jacques de. La légende dorée. Paris : Gallimard, 2004, p. 48.

11. - COURTILLÉ, Anne. Histoire de la peinture murale dans l'Auvergne du Moyen Âge. Brioude : Watel, 1983, p. 127. L'iconographie du martyre de saint André a varié au cours du Moyen Âge mais c'est cette forme qui prévaut aux XIII et XIV ${ }^{\mathrm{e}}$ siècles. Voir RÉAU, Louis. Iconographie de l'art chrétien. Paris : Presses universitaires de France, 1955-1959, t. I-1, p. 76-84.

12. - Tous mes remerciements vont aux membres du GRPM et tout particulièrement à Christian Davy pour m'avoir suggéré cette interprétation lors d'un voyage d'étude en mai 2012. 
13. - Sur l'apparition de la variante particulière du quadrilobe étoilé : DAUSSY, Stéphanie Diane, TIMBERT, Arnaud. "Les portails de la cathédrale de Noyon: la sculpture du XIII siècle ». Les cahiers de l'Histoire de l'Art, 2013, 11, à paraître.

14. - GRODECKI, Louis, BRISAC, Catherine. Gothic Stained Glass, 1200-1300. Ithaca, New York: Cornell University Press, 1985, p. 150.

15. - Sur Auxerre : NORSTRÖM, Folke. The Auxerre Reliefs. A Harbiger of the Renaissance in France during the Reign of Philip le Bel. Uppsala : Almquist \& Wiksell International, 1974; sur Rouen: SCHLICHT, Markus. La cathédrale de Rouen vers 1300. Caen : Société des Antiquaires de Normandie, 2005, p. 203-242.

16. - DIDIER, Marie-Hélène. Les peintures murales de la Manche. 40 ans d'études et de restaurations. Collection Patrimoine, ca. 1999, p. 66-73.

17. - Columbia (South Carolina), Museum of Art, œuvre datée vers 1275-1285 (?) et attribuée au Maestro di Vicchio a Rimaggio par TARTUFERI, Angelo. La pittura a Firenze nel duecento. Florence : Alberto Bruschi, 1990, fig. 226; datée vers 1290 et attribuée à Deodato Orlandi sur le site du musée de Columbia.

18. - PARK, David. Survey of the Medieval and Later Polychromy of Worcester Cathedral : A Report for the Dean and Chapter (Rapport inédit du Courtauld Institute of Art). Londres, 1997, n 25.

19. - MARTINDALE, Andrew. "St Stephen's Chapel, Westminster, and the Italian Experience». Dans BUCKTON, David, HESLOP, T. A. Studies in Medieval Art and Architecture presented to Peter Lask o. Phoenix Mill et al. : Alan Sutton, the Trustees of the British Museum, 1994, p. 102-112.

20. - SAUVAL, Henri. Histoire et recherches des antiquités de la ville de Paris. Paris : Charles Moette, Jacques Chardon, 1724, t. II, p. 281. Voir aussi BOURNON, Fernand. «L'hôtel royal Saint-Pol à Paris ». Mémoires de la Société de l'Histoire de Paris et l'île-de-France, 6, 1879, p. 54-179, particulièrement p. 98.

21. - À ce sujet, voir par exemple : AVRIL, François. L'enluminure à la cour de France au XIve siècle. Paris : Chêne, 1978, p. 10-11.

22. - Sur les origines et les sources de la légende de saint Eustache, voir : MEYER, Paul. «Les légendes hagiographiques ». Histoire littéraire de la France, 1906, 33, p. 329-459; MONTEVERDI, Angelo. «La leggenda di S. Eustachio ». Studi medievali, 1909-1910, 3, p.169-229 et 392-498; HEFFERNAN, Thomas. "An Analysis of the Narrative Motifs in the Legend of St Eustace». Medievalia et Humanistica, 1975, 6, p. 63-89; MANHÈS-DEREMBLE, Colette, DEREMBLE, Jean-Paul. Les vitraux narratifs de la cathédrale de Chartres. Paris : Le léopard d'Or, 1993, p. 91-96.

23. - MANHÈS-DEREMBLE, Colette, DEREMBLE, Jean-Paul. Les vitraux narratifs de la cathédrale de Chartres. Paris : Le léopard d'Or, 1993, p. 91-94. Voir pour une liste des manuscrits existants : MEYER, Paul. « Les légendes hagiographiques ». Histoire littéraire de la France, 1906, 33, p. 329-459 ; MONTEVERDI, Angelo. «La leggenda di S. Eustachio ». Studi medievali, 1909-1910, 3, p. 169-229 et 392-498, particulièrement p. 396-445. Pour leur édition: PETERSEN, Holger. «Trois versions inédites de la Vie de saint Eustache en vers français ». Romania, 1922, 48, p. 365-402 (avec une liste des éditions à cette date p. 365) ; PETERSEN, Holger. "Trois versions inédites de la Vie de saint Eustache en vers français, II ». Romania, 1925, 51, p. 363-396 ; Idem, Romania, 1926, 52, p. 37-74.

24. - VORAGINE, Jacques de. La légende dorée. Paris : Gallimard, 2004, p. 881-888 (chapitre 157).

25. - GOLDEN, Judith. «Images of Instruction, Marie de Bretagne, and the Life of St. Eustace as Illustrated in British Library Ms. Egerton 745 ». Dans HOURIHANE, Colum. Insights and Interpretations: Studies in Celebration of the eighty-fifth anniversary of the Index of Christian Art. Princeton: Index of Christian Art, Princeton University Press, 2002, p. 60-84. La liste de 22 manuscrits, vitraux, peintures murales, objets en ivoire et sculptures du XI ${ }^{\mathrm{e}}$ au XIV siècle n'est malheureusement pas dépourvue d'erreurs. Ainsi, le coffret du V\&A Museum ne correspond pas au ${ }^{\circ} 1248$ de Koechlin (1924), qui concerne un cor de chasse décoré des scènes du saint. Koechlin ne connaissait pas le coffret, actuellement visible sur le site du musée: http:// collections.vam.ac.uk/item/0312887/casket/. Mes remerciements vont à Glyn Davis (V\&A 
Museum) pour m'avoir aidée dans cette quête. Par ailleurs, il faut ajouter à la liste de Golden le cycle peint découvert à Montpellier en 1999 et daté de la fin du XIII ${ }^{\mathrm{e}}$ siècle environ (SOURNIA, Bernard, VAYSSETTES, Jean-Louis. «La grand-chambre de l'hostal des Carcassonne à Montpellier ». Bulletin Monumental, 2002, 160, 1, p. 121-131). Il en reste cinq scènes, situées dans la partie supérieure des murs de la grand-chambre de l'hostal des Carcassonne, de l'Apparition du Christ dans les bois du cerf aux enfants enlevés par des animaux sauvages.

26. - MANHÈS-DEREMBLE, Colette, DEREMBLE, Jean-Paul. Les vitraux narratifs de la cathédrale de Chartres. Paris : Le léopard d'Or, 1993, p. 43, 262-263.

27. - RANDALL, R. H. The Golden Age of Ivory. Gothic Carvings in North American Collections. New York : Hudson Hills Press, 1993, p. 121-122.

28. - Seul le vitrail du Mans (milieu du XIV ${ }^{\mathrm{e}}$ siècle) présente deux scènes pour la chasse, Eustache sonnant l'olifant dans la première, et pourchassant le cerf dans la seconde. Les Vitraux du Centre et des Pays de la Loire. Paris: CNRS, 1981, p.249, et http://www.medievalart.org.uk/ LeMans/102_pages/LeMans_Bay102_Key.htm, scènes C1 et B1.

29. - LE POGAM, Pierre-Yves. Les premiers retables (XII - début du XV siècle). Une mise en scène du sacré. Cat. expo. Paris, Milan: Musée du Louvre, Officina Libraria, 2009, p. 245.

30. - Cette scène ne doit pas être confondue avec la vision de Théopiste présente dans certains cycles, par exemple dans le vitrail d'Erfurt, vers 1375-1380 (DRACHENBERG, Erhard. Die mittelalterliche Glasmalerei im erfurter Dom. Berlin, Vienna, Cologne, Graz: Akademie-Verlag, Hermann Böhlaus, 1980, p. 304-312). Là, la vision est matérialisée par l'apparition d'un ange, alors qu'à Lachapelle-sous-Gerberoy, Théopiste au seuil de la porte est tournée vers son mari.

31. - British Library, Egerton 745. Sur ce manuscrit: GOLDEN, Judith. «Images of Instruction, Marie de Bretagne, and the Life of St. Eustace as Illustrated in British Library Ms. Egerton $745 »$. Dans HOURIHANE, Colum. Insights and Interpretations: Studies in Celebration of the eighty-fifth anniversary of the Index of Christian Art. Princeton : Index of Christian Art, Princeton University Press, 2002, p. 60-84; sur le baptême de la famille, voir le tableau synthétique p. 75.

32. - BONNET-LABORDERIE, Pierrette. "Les peintures murales du XII ${ }^{\mathrm{i} e}-\mathrm{XI}^{\mathrm{v} e}$ siècle de l'Oise ". Dans L'art gothique dans l'Oise et ses environs. Beauvais : GEMOB, 2001, p. 295-310, particulièrement p. 304, où une autre interprétation est proposée pour cette scène et celle d'Eustache retrouvant les siens.

33. - Sur le premier texte, voir FISHER, John. «La Vie de saint Eustache par Pierre de Beauvais ». The Romanic Review, 1917, 8, 1, p.1-67; sur le deuxième, PETERSEN, Holger. "Trois versions inédites de la Vie de saint Eustache en vers français ». Romania, 1922, 48, p. 365-402; et sur le troisième, PETERSEN, Holger. "Trois versions inédites de la Vie de saint Eustache en vers français, II ». Romania, 1925, 51, p. 363-396. L'autre Vie publiée en 1926 par Petersen, d'après un manuscrit $\mathrm{du} \mathrm{XV}$ siècle copié sur un autre plus ancien provenant du nord de la France, diffère dans les détails des trois autres, ainsi que du cycle peint de Lachapelle-sous-Gerberoy (PETERSEN, Holger. «Trois versions inédites de la Vie de saint Eustache en vers français, III ». Romania, 1926, 52, p. 37-74).

34. - FISHER, John. « La Vie de saint Eustache par Pierre de Beauvais ». The Romanic Review, 1917, 8, 1, p. 12-13, v. 129-158 ; PETERSEN, Holger. « Trois versions inédites de la Vie de saint Eustache en vers français ». Romania, 1922, 48, p. 373, v. 125-152 ; Idem, Romania, 1925, 51, p. 377-378, v. 65-80.

35. - FISHER, John. «La Vie de saint Eustache par Pierre de Beauvais ». The Romanic Review, 1917, 8, 1, p. 14-18, v. 170-288; PETERSEN, Holger. «Trois versions inédites de la Vie de saint Eustache en vers français ». Romania, 1922, 48, p. 373-375, v. 157-314 et p. 379, v. 573-614 ; PETERSEN, Holger. « Trois versions inédites de la Vie de saint Eustache en vers français, II ». Romania, 1925, 51, p. 378-380, v. 85-162. 
36. - FISHER, John. «La Vie de saint Eustache par Pierre de Beauvais ». The Romanic Review, 1917, 8, 1, p. 21, v. 308-310 ; PETERSEN, Holger. « Trois versions inédites de la Vie de saint Eustache en vers français ». Romania, 1922, 48, p. 379, v. 615-624 ; Idem, Romania, 1925, 51, p. 380, v. 163-164.

37. - Sur l'interprétation de cet épisode, voir HEFFERNAN, Thomas. « An Analysis of the Narrative Motifs in the Legend of St Eustace ». Medievalia et Humanistica, 1975, 6, p. 63-89, particulièrement p. 77.

38. - FISHER, John. « La Vie de saint Eustache par Pierre de Beauvais ». The Romanic Review, 1917, 8, 1, p. 20, v. 356-382 ; PETERSEN, Holger. « Trois versions inédites de la Vie de saint Eustache en vers français ». Romania, 1922, 48, p. 380, v. 651-698 ; Idem, Romania, 1925, 51, p. 380, v. 180-188.

39. - FISHER, John. «La Vie de saint Eustache par Pierre de Beauvais ». The Romanic Review, 1917, 8, 1, p. 31, v. 705-708 ; PETERSEN, Holger. « Trois versions inédites de la Vie de saint Eustache en vers français ». Romania, 1922, 48, p. 385, v. 1065-1068; Idem, Romania, 1925, 51, p. 385, v. 389-398. 40. - BONNET-LABORDERIE, Pierrette. "Les peintures murales du XII ${ }^{\mathrm{i} e}-\mathrm{XI}^{\mathrm{v} e}$ siècle de l'Oise ». Dans L'art gothique dans l'Oise et ses environs. Beauvais : GEMOB, 2001, p. 301-304.

41. - Lexikon der christlichen Ikonographie. Rome, Freiburg im Breisgau et al. : Herder, 1968-1976, t. 1, col. 245 ; VICAIRE, M.-H. «La place des œuvres de miséricorde dans la pastorale en pays d'Oc ». Dans Assistance et Charité, Cahiers de Fanjeaux 13. Toulouse: Privat, 1978, p. 21-44, particulièrement p. 23-29 ; VAN BÜHREN, Ralf. Die Werke der Barmherzigkeit in der Kunst der 12. - 18. Jahrhunderts. Zum Wandel eines Bildmotivs vor dem Hintergrund neuzeitlicher Rhetorikrezeption. Hildesheim, Zürich, New York : Georg Olms, 1998, p. 25-26.

42. - VAN BÜHREN, Ralf. Die Werke der Barmherzigkeit in der Kunst der 12. - 18. Jahrhunderts. Zum Wandel eines Bildmotivs vor dem Hintergrund neuzeitlicher Rhetorikrezeption. Hildesheim, Zürich, New York : Georg Olms, 1998, p. 37.

43. - BEYER, Victor. La cathédrale de Strasbourg. Paris : La bibliothèque des arts, 1970, p. 482-493.

44. - Les lettres qui apparaissent sur la photographie publiée par P. Bonnet-Laborderie, sur lesquelles les peintures sont en meilleur état, semblent différentes.

45. - FISHER, John. «La Vie de saint Eustache par Pierre de Beauvais ». The Romanic Review, 1917, 8, 1, p. 11, v. 83-94; PETERSEN, Holger. «Trois versions inédites de la Vie de saint Eustache en vers français ». Romania, 1922, 48, p. 372, v. 75-88 et p. 373, v. 177-184 ; idem, Romania, 1925, 51, p. 376-377, v. 24-34 ; Idem, Romania, 1926, 52, p. 52, v. 12-13.

46. - VORAGINE, Jacques de. La légende dorée. Paris : Gallimard, 2004, p. 881.

47. - FISHER, John. «La Vie de saint Eustache par Pierre de Beauvais ». The Romanic Review, 1917, 8, 1, p. 15, v. 218-222 ; PETERSEN, Holger. «Trois versions inédites de la Vie de saint Eustache en vers français ». Romania, 1922, 48, p. 374, v. 247-250 ; Idem, Romania, 1925, 51, p. 379, v. 117-118.

48. - MOLLAT, Michel. Les pauvres au Moyen Âge. Paris : Hachette, 1978, p. 134 ; VAN BÜHREN, Ralf. Die Werke der Barmherzigkeit in der Kunst der 12. - 18. Jahrhunderts. Zum Wandel eines Bildmotivs vor dem Hintergrund neuzeitlicher Rhetorikrezeption. Hildesheim, Zürich, New York : Georg Olms, 1998, p. 27-29.

49. - Ainsi pour le manuscrit British Library Royal $19 \mathrm{C} \mathrm{I}$, fol. 80-80v. Voir à ce sujet: BOTANA, Federico. «Virtuous and Sinful Uses of Temporal Wealth in the Breviari d'Amor of Matfre Ermengaud (Ms Bl Royal 19.C.I) ». Journal of the Warburg and Courtauld Institutes, 2004, 67, p. 49-80, particulièrement p.59-62. C'est le manuscrit de la Bibliothèque nationale de Russie, MC. Prov. F. V. IV.1, fol. 52, datant de la fin du XIII ${ }^{\mathrm{e}}$ siècle, qui est illustré ici.

50. - GARDELLES, Jacques. «La chasse dans l'architecture et le décor des châteaux au Moyen Âge ». Dans CHASTEL, André. Le château, la chasse et la forêt. Bordeaux: Sud-Ouest, 1990, p. 129-139.

51. - JUHEL, Vincent. « Le château médiéval du Vaudreuil (Eure) et ses peintures murales du XIV siècle ». Dans Vivre dans le Donjon au Moyen Âge. Vendôme : Cherche-Lune, 2005, p. 135-141.

52. - Sur ce décor, voir : VICTOIR, Géraldine. «Profane ou religieux ? Le choix des sujets dans les demeures de laïcs et d'ecclésiastiques en Picardie au XIV ${ }^{\mathrm{e}}$ siècle ». Dans Les peintures murales dans 
la demeure, 2007: http://www.cg49.fr/culture/peintures_murales/medias/pdf/ geraldine_victoir.pdf. VICTOIR, Géraldine. «La camera comme un lieu privilégié du religieux dans la demeure de laïcs : l'apport de la peinture murale ». Dans HECK, Christian. Thèmes religieux et thèmes profanes dans l'image médiévale : transferts, emprunts, oppositions, à paraittre.

53. - BRAUNFELS, Wolfgang. Die Verkündigung. Düsseldorf: Schwann, 1949, p. XIII. Sur ces mosaïques et pour une réévaluation de leur date, voir TOMEI, Alessandro. Pietro Cavallini. Cinisello Balsamo (Milano) : Silvana Editoriale, 2000, p. 23-51.

54. - ROBB, David. "The Iconography of the Annunciation in the Fourteenth and Fifteenth Centuries ». The Art Bulletin, 1936, 18, 4, p. 480-526, particulièrement p. 482.

55. - ROBB, David. «The Iconography of the Annunciation in the Fourteenth and Fifteenth Centuries ». The Art Bulletin, 1936, 18, 4, p. 482-485.

56. - ROBB, David. "The Iconography of the Annunciation in the Fourteenth and Fifteenth Centuries ». The Art Bulletin, 1936, 18, 4, p. 485 ; SCHILLER, Gertrud. Iconography of Christian Art. Vol. 1: Christ's Incarnation, Childhood, Baptism, Temptation, Transfiguration, Works and Miracles. Londres : Lund Humphries, 1972, p. 47.

57. - New York, Metropolitan Museum of Art, The Cloisters Collection, 54.1.2, fol. 16. Sur Pucelle et les Heures de Jeanne d'Evreux, voir par exemple MORAND, Kathleen. Jean Pucelle. Oxford: Clarendon Press, 1962 ; HAMBURGER, Jeffrey. "The Waddesdon Psalter and the Shop of Jean Pucelle ». Zeitschrift für Kunstgeschichte, 1981, 44, 3, p. 243-257 ; KRIEGER, Michaela. « Die "Heures de Jeanne d'Evreux" und das Pucelle-Problem ». Wiener Jahrbuch für Kunstgeschichte, 1989, 42, p. 101-132.

58. - ROBB, David. "The Iconography of the Annunciation in the Fourteenth and Fifteenth Centuries ». The Art Bulletin, 1936, 18, 4, p. 493, 500 ; AVRIL, François. L'enluminure à la cour de France au XIV ${ }^{e}$ siècle. Paris : Chêne, 1978, p. 14-15, 44.

59. - BnF, nouv. acq. lat. 3145, STERLING, Charles. La peinture médiévale à Paris, 1300-1500. Paris : Bibliothèque des Arts, 1987, p. 104-106.

60. - KURMANN, Peter, KURMANN-SCHWARZ, Brigitte. «Das mittlere und sudliche Westportal der Kathedrale von Meaux : Repräsentanten der Pariser Plastik aus dem zweiten Viertel des 14. Jahrhunderts und ihr politischer Hintergrund». Zeitschrift für Schweizerische Archaologie und Kunstgeschichte, 1986, 43, 1, p. 37-57, particulièrement p. 47-49.

61. - VAN DIJK, Ann. «The Angelic Salutation in Early Byzantine and Medieval Annunciation Imagery ». The Art Bulletin, 1999, 81, 3, p. 420-436.

62. - VAN DIJK, Ann. "The Angelic Salutation in Early Byzantine and Medieval Annunciation Imagery ». The Art Bulletin, 1999, 81, 3, p. 422.

63. - BONNET-LABORDERIE, Pierrette. "Les peintures murales du XII ${ }^{\mathrm{i} e}-\mathrm{XI}^{\mathrm{v} e}$ siècle de l'Oise ". Dans L'art gothique dans l'Oise et ses environs. Beauvais: GEMOB, 2001, p. 302, a suggéré de lire également une bordure or, mais il semble plus probable qu'il s'agisse du contour jaune du blason, blanc sur fond blanc. Notons que l'interprétation des émaux est ici hasardeuse, étant donné que le peintre n'avait que des tons ocre à sa disposition. C'est pourquoi nous ne mentionnons pas celui des losanges (qui sont en fait jaune cernés de rouge).

64. - Le blason d'un seigneur anonyme du Beauvaisis, listé dans l'armorial Wijnbergen, est similaire mais il est brisé d'un lambel et le fond est d'argent plutôt que d'hermine. Un autre présente la même charge mais des couleurs opposées; il a été identifié par Jéquier comme appartenant à Jean d'Auchy par comparaison avec l'armorial Montjoie-Chandon (également connu sous le nom d'armorial Le Breton et disponible sur internet : http://www.culture.gouv.fr/ Wave/image/archim/0008/dafanch06_a103502n00001_2.htm) (ADAM-EVEN, Paul, JEQUIER, Léon. «L'armorial Wijnbergen». Dans Archives héraldiques suisses, 1951-1954, n 1032-1033). Deux localités dans le Beauvaisis répondent à ce nom, situées à respectivement 10 et $25 \mathrm{~km}$ de Lachapelle-sous-Gerberoy. Il reste difficile d'interpréter et de mettre en lien ces maigres éléments. 
65. - PILLET, Jean. Histoire du château et de la ville de Gerberoy de siècle en siècle. Rouen, 1679, p. 169 ; BEAUVILLÉ, Victor de. Recueil de documents inédits concernant la Picardie. Paris: Imprimerie nationale, 1877, t. 3, XXV, CXXXV, CXXXVI, CLIV, CLV, CLVI.

66. - Archives départementales de l'Oise, G7431.

67. - PILLET, Jean. Histoire du château et de la ville de Gerberoy de siècle en siècle. Rouen, 1679, p. 169, 210.

68. - Archives départementales de l'Oise, G7434, Mémoire concernant le gros du curé de la Chapellesous-Gerberoy, vers 1684, d'après des extraits d'un registre fait en 1404 environ par Henri Baudouin, curé du lieu, fol. $1 \mathrm{v}, 2 \mathrm{r}$.

69. - Archives départementales de l'Oise, G7438.

\section{RÉSUMÉS}

La chapelle seigneuriale située au nord de l'église de Lachapelle-sous-Gerberoy (Oise) a été décorée vers le milieu du XIV siècle d'un cycle de la vie de saint Eustache exceptionnellement développé, comprenant une série d'images montrant le saint et sa femme accomplissant les œuvres de miséricorde. Des figures de saints et une Annonciation monumentale complètent l'ensemble. L'analyse des images permet de mettre en avant le lien que le cycle entretient avec certaines des Vies littéraires, ainsi que le rôle de modèle de piété et de charité que pouvait exercer l'histoire d'Eustache sur le commanditaire et sa femme.

The chapel located to the north of the church of Lachapelle-sous-Gerberoy (Oise) was adorned around the middle of the 14th century with an exceptionally long cycle of the life of saint Eustace, which comprises a series of images showing the saint and his wife carrying out the Works of Mercy. The scheme also features figures of saints and a monumental Annunciation. An analysis of the images suggests that the structure of the narrative derives from written Lives of Eustace and that the cycle was particularly suited to act as a model of piety and charity for a lay couple.

\section{INDEX}

Mots-clés : Moyen Âge, peinture murale, Oise, saint Eustache, chasse, œuvres de miséricordes, cycle narratif, Annonciation, saints, quadrilobes

\section{AUTEUR}

\section{GÉRALDINE VICTOIR}

Maître de conférences en histoire de l'art médiéval, université Paul-Valéry - Montpellier 3

g.victoir@gmail.com 